\title{
The role of domain-general cognitive control in language comprehension
}

\author{
Evelina Fedorenko* \\ Psychiatry Department, Massachusetts General Hospital, Charlestown, MA, USA
}

Edited by:

Tamara Swaab, University of

California, USA

Reviewed by:

Olaf Hauk, MRC Cognition and Brain

Sciences Unit, UK

David Caplan, Massachusetts

General Hospital, USA

*Correspondence:

Evelina Fedorenko, Psychiatry

Department, Massachusetts

General Hospital, Building 149

East 13th Street, Charlestown,

MA 02129, USA

e-mail: evelina9@mit.edu
What role does domain-general cognitive control play in understanding linguistic input? Although much evidence has suggested that domain-general cognitive control and working memory resources are sometimes recruited during language comprehension, many aspects of this relationship remain elusive. For example, how frequently do cognitive control mechanisms get engaged when we understand language? And is this engagement necessary for successful comprehension? I here (a) review recent brain imaging evidence for the neural separability of the brain regions that support high-level linguistic processing vs. those that support domain-general cognitive control abilities; (b) define the space of possibilities for the relationship between these sets of brain regions; and (c) review the available evidence that constrains these possibilities to some extent. I argue that we should stop asking whether domain-general cognitive control mechanisms play a role in language comprehension, and instead focus on characterizing the division of labor between the cognitive control brain regions and the more functionally specialized language regions.

Keywords: multiple-demand system, cognitive control, fMRI, sentence processing, language, modularity
Language is one of few cognitive abilities unique to our species. However, language has neither evolved nor does it exist in isolation from other cognitive and neural machinery (e.g., Christiansen and Chater, 2008; cf. Fodor, 1983), which may be largely shared between humans and non-human animals (e.g., van Horik and Emery, 2011; Kaas, 2013). This machinery includes sensory and motor systems, memory and attention mechanisms, and mechanisms that support social cognition, among others. This paper examines the relationship between high-level language processing and domain-general cognitive control, with a focus on the brain systems that support these cognitive capacities.

Brain regions that support domain-general cognitive control have been implicated in a wide range of goal-directed behaviors (see e.g., Duncan, 2010, for a recent review). In the domain of language, cognitive control has been shown to play an important role in language production, based on behavioral evidence (e.g., Alm and Nilsson, 2001; Roelofs and Piai, 2011; Strijkers et al., 2011), brain imaging studies (e.g., Müller et al., 1997; Ojemann et al., 1998; Indefrey and Levelt, 2004; Kerns et al., 2004; Haller et al., 2005; Shuster and Lemieux, 2005; Alario et al., 2006; Bohland and Guenther, 2006; Shapiro et al., 2006; Basho et al., 2007; Harrington et al., 2007; Troiani et al., 2008; den Ouden et al., 2009; Eickhoff et al., 2009; Wilson et al., 2009; Brendel et al., 2010; Tremblay and Small, 2011; Adank, 2012; Geranmayeh et al., 2012; Grande et al., 2012; Heim et al., 2012; Delnooz et al., 2013) and investigations of patients with brain damage (e.g., Ziegler et al., 1997; Nestor et al., 2003; Ash et al., 2010; Wilson et al., 2010; Baldo et al., 2011; Coelho et al., 2012; Endo et al., 2013). Indeed, planning and producing linguistic utterances bears intuitive similarity to non-linguistic goal-directed behaviors like reaching (e.g., Bernstein, 1996; Culham and Valyear,
2006; Grafton and Hamilton, 2007; Ridderinkhof et al., 2011) or playing a musical instrument (e.g., Meister et al., 2004). In contrast, language comprehension (i.e., the process of extracting meaning from the linguistic signal) is, or at least can be, a more "passive," automatic process: just like we can't help but recognize a face upon seeing a face-like configuration (e.g., Suzuki and Cavanagh, 1995; see Palermo and Rhodes, 2007 for a review), we often can't help but interpret linguistic input if we know the language in question (e.g., Fodor, 1983; Pinker, 1994; Shtyrov and Pulvermüller, 2007; Pulvermüller et al., 2008; Wild et al., 2012). That said, much behavioral and neuroimaging evidence (to be reviewed in section Narrowing Down the Hypothesis Space for the Relationship between Language Processing Mechanisms and Cognitive Control Mechanisms) suggests that domain-general cognitive control mechanisms do sometimes get recruited during language comprehension. In this position paper, I discuss two inter-related aspects of the relationship between language processing and cognitive control that are not yet well-understood: (i) when (i.e., under what circumstances) the cognitive control mechanisms get engaged during language understanding; and (ii) whether this engagement is necessary for comprehension (i.e., whether understanding linguistic input requires domain-general cognitive control mechanisms, or whether those mechanisms are helpful but non-essential).

The paper is structured as follows: First, I introduce the brain regions that support high-level language processing vs. domaingeneral cognitive control, and discuss the evidence for the neural separability of these two sets of brain regions. I then introduce two questions about the relationship between language comprehension and cognitive control and define the hypothesis space for each. I then proceed to discuss the arguments and 
evidence-from behavioral and brain imaging work in healthy and brain-damaged populations - that constrain these hypotheses. Finally, I summarize and conclude.

\section{HIGH-LEVEL LANGUAGE PROCESSING BRAIN REGIONS AND DOMAIN-GENERAL COGNITIVE CONTROL BRAIN REGIONS HIGH-LEVEL LANGUAGE-PROCESSING BRAIN REGIONS}

A number of regions in the human brain robustly respond to linguistic input. These regions include most prominently regions on the lateral surface of the left frontal, temporal and parietal cortices, but also a number of other cortical, subcortical and cerebellar regions (Figure 1A). Originally discovered in patients with brain damage (e.g., Broca, 1861; Dax, 1863; Wernicke, 1874/1969; Geschwind, 1970), these regions have been observed in PET and fMRI since the earliest days of brain imaging research (e.g., Petersen et al., 1988; Petersen and Fiez, 1993; Binder et al., 1997). These regions are consistent (albeit variable in their exact topography; e.g., Fedorenko et al., 2010) across individuals (e.g., Frost et al., 1999; Allendorfer et al., 2012), languages (e.g., Chee et al., 1999a,b; Illes et al., 1999; Klein et al., 1999; Hernandez et al., 2001; Pu et al., 2001; Hasegawa et al., 2002; Chee et al., 2003; Mahendra et al., 2003; Briellmann et al., 2004; see e.g., van Heuven and Dijkstra, 2010 and Sebastian et al., 2011 for reviews), modality of presentation (e.g., Chee et al., 1999c; Pinel et al., 2007; Buchweitz et al., 2009; Fedorenko et al., 2010; Braze et al., 2011) and developmental experiences, including complete sensory deprivation in the auditory or visual modality (Neville et al., 1998; Newman et al., 2010; Bedny et al., 2011). Furthermore, these regions can be quickly (in $\sim 10-15 \mathrm{~min}$ ) and reliably identified in individual participants (Fedorenko et al., 2010), and they are stable within an individual over time (Figure 1B; Fedorenko et al., 2010; Mahowald and Fedorenko, in preparation), as well as being robust to changes in the materials, modality of presentation, and task (Figure 1C), and language for bilingual speakers (Figure 1D).

This set of brain regions can be identified with a variety of contrasts that compare a more language-like stimulus with a less language-like stimulus ${ }^{1}$ (e.g., words vs. fixation or tones-Binder et al., 1997; Diaz and McCarthy, 2009; words vs. pseudowords-Petersen et al., 1990; sentences vs. fixationKuperberg et al., 2003; sentences vs. false font or consonant strings-Bavelier et al., 1998; Robertson et al., 2000; Noppeney and Price, 2004; sentences vs. lists of words or pseudowordsSnijders et al., 2009; Fedorenko et al., 2010; Fedorenko and Kanwisher, 2011). Language-like-ness can be operationalized in terms of the amount of overlap between the stimulus and natural language. For example, phonotactically legal pseudowords and words match the sound-level properties of natural language, real words further match the lexical representations, and phrases or sentences match both lexical representations as well as

\footnotetext{
${ }^{1}$ Stimulus manipulations are not the only way to activate language-responsive brain regions: a number of studies have used task contrasts (e.g., performing a semantic task vs. a control perceptual task on sentences; Ferstl and von Cramon, 2001). Such contrasts presumably force comprehenders to more deeply process the relevant (linguistic) aspects of the signal in the critical vs. in the control, perceptual, conditions.
}

larger structural / meaning units. And the process of language comprehension can be thought of, at least in part, as finding matches between the input and the stored language knowledge representations, with more/better matches leading to greater responses. In the remainder of the paper I will refer to this set of brain regions as the "language system"2,3.

The stability of language activations within individuals across time and their robustness to variation in many properties of the defining contrast suggest that the language system may constitute a "natural kind," i.e., a meaningful and stable subset of the brain. Two further lines of evidence suggest that these regions constitute an integrated functional system ${ }^{4}$. The first comes from studies of resting-state functional correlations, often referred to as "functional connectivity" (e.g., Fox and Raichle, 2007). In particular, the entire language system discussed above consistently emerges in the analyses of low-frequency oscillations across the brain during rest (e.g., Turken and Dronkers, 2011; Newman et al., 2013; Blank et al., submitted; see e.g., Catani et al., 2005, for DTI data consistent with the idea that these regions form a network). Although the interpretation of resting-state correlation patterns is still debated, these correlations appear to capture stable aspects of the functional organization of the human brain that persists across different mental states including sleep (e.g., Horovitz et al., 2008) and anesthesia (e.g., Vincent et al., 2007), and in some cases goes beyond known anatomical connections (e.g., Honey et al., 2009).

The second line of evidence comes from investigations of cortical thinning patterns in primary progressive aphasia, a neurodegenerative condition that disproportionately, and perhaps selectively, affects language processing (e.g., Mesulam, 2001; Grossman and Ash, 2003; Gorno-Tempini et al., 2004). The pattern of cortical thinning in this disorder-especially in the semantic variant-is strikingly similar to the functional activations for the contrasts, like e.g., sentences $>$ pseudoword lists (e.g., Listerud et al., 2009; Rohrer et al., 2009; Dickerson, 2011;

${ }^{2}$ It is worth noting that referring to these "high-level" language processing brain regions as the "language system" does not imply that no other brain regions are important for language. In fact, we know that sensory regions (both in the auditory cortices-e.g., Belin et al., 2000; Binder et al., 2000; see DeWitt and Rauschecker, 2013, for a recent review—and in the ventral visual cortex-e.g., Nobre et al., 1994; McCandliss et al., 2003; Baker et al., 2007) play an important role at the early stages of processing auditory/visual language input. Furthermore, regions of the motor and premotor cortex are engaged in articulatory processing (e.g., Bohland and Guenther, 2006). However, I here focus on the higher-level language processing regions and will use the term "language system" to refer to just the latter subset of the languagerelevant machinery (see Fedorenko and Thompson-Schill, 2014, for further discussion).

${ }^{3}$ The term "network" is frequently used to refer to sets of brain regions that share functional properties (e.g., Sporns, 2010; Power et al., 2011). However, the available human data do not at present afford strong inferences about anatomical inter-regional connections. So, the term "system" is more accurate, since it is consistent with but does not imply anatomical connectivity.

${ }^{4}$ The notion of a "system" highlights the similarities among a set of brain regions and the differences between these regions and the rest of the brain, but it does not imply a lack of differences among these regions. Different components of the language system may support somewhat different aspects of language processing. 


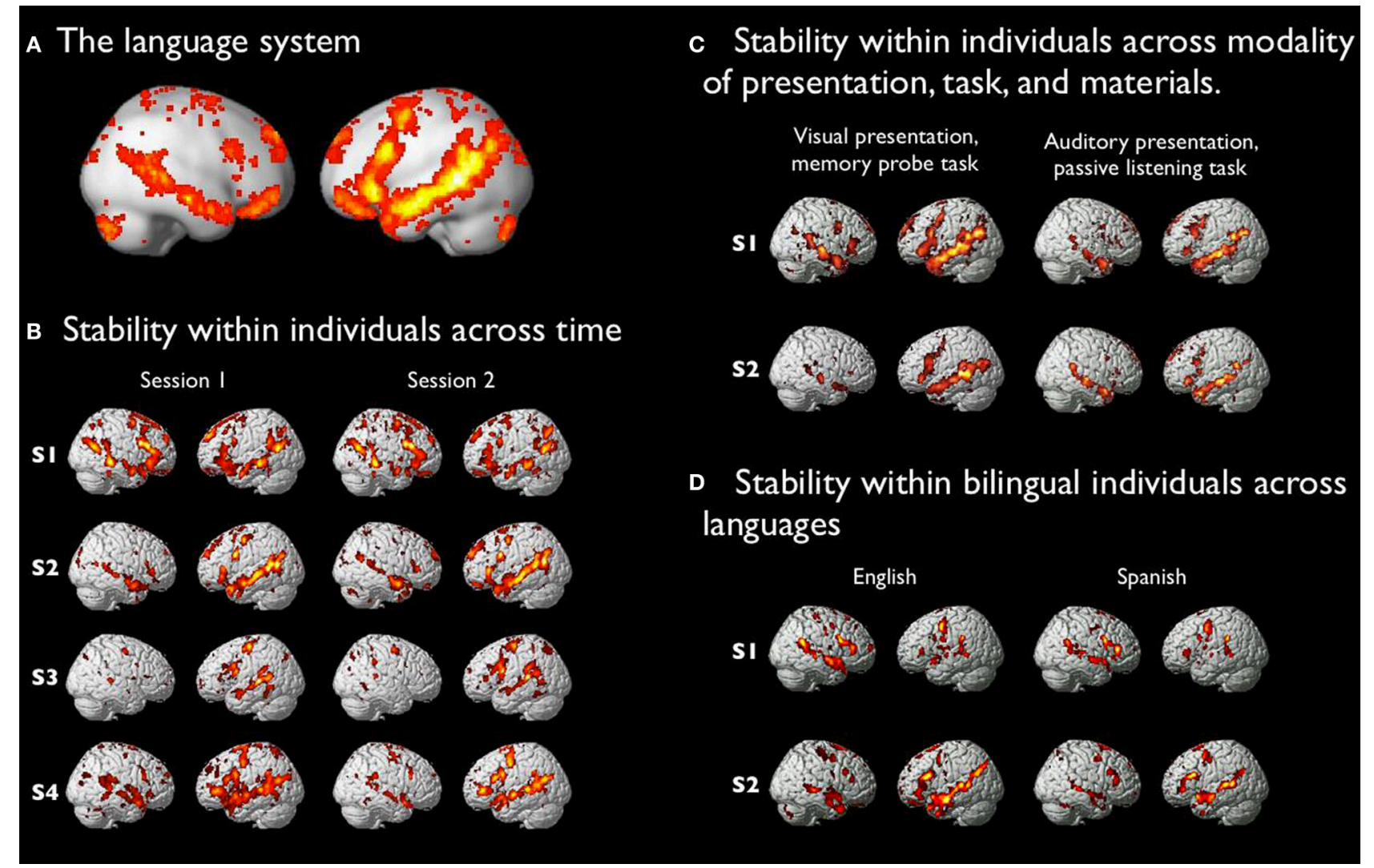

FIGURE 1 | (A) The language system: a set of brain regions that are robustly and consistently activated by linguistic input (see (Fedorenko and Thompson-Schill, 2014); Fedorenko and Thompson-Schill, for further discussion of how to define the "language system/network"). A probabilistic activation overlap map for the contrast between sentences and sequences of pseudowords (adapted from Fedorenko et al., 2010). Warmer colors indicate greater proportions of subjects showing a reliable sentences $>$ pseudoword lists effect. (B) Activation maps for four sample subjects tested on the sentences $>$ pseudoword lists contrast across two independent scanning sessions, between 1 and 6.5 months apart. (For subjects 2 and 4, non-overlapping sets of materials were used across the two sessions). (C) Activation maps for two sample subjects for a contrast between sentences and pseudoword lists presented visually with a memory-probe task (participants had to decide after each sentence or pseudoword sequence whether the probe word/pseudoword appeared in the preceding stimulus), and a contrast between sentences and pseudoword lists (with non-overlapping materials) presented auditorily with a passive listening task. (D) Activation maps for two sample English-Spanish bilingual subjects for a contrast between sentences and pseudoword lists in the two languages. (The materials across the two languages were not related to each other in any way, so the similarity is not likely to be due to similar semantic content).
Gorno-Tempini et al., 2011; Rogalski et al., 2011). The precise mechanisms of degeneration constitute an area of active research, but one influential proposal that has been put forward argues for propagation along transsynaptic connections (Seeley et al., 2009).

In summary, a set of regions in the human brain (a) robustly respond to language input (with responses decreasing as the stimulus becomes less language-like, or when attention is drawn away from the linguistic properties of the stimulus and toward its perceptual features); (b) show strong correlations in their time courses during rest; and (c) are jointly susceptible to neurodegeneration in primary progressive aphasia. Together, these sets of findings suggest that these regions constitute a functional system. Given that these brain regions get activated by linguistic input and given that damage to these regions in mature brains leads to language deficits (e.g., Damasio, 1992; Bates et al., 2003), it is natural to assume that they play an important (and causal) role in interpreting the linguistic signal, although some components of this system have been argued to not be exclusively engaged by language but to instead support more abstract semantic processing (e.g., Hagoort et al., 2004; Patterson et al., 2007; Binder et al., 2009).

\section{DOMAIN-GENERAL COGNITIVE CONTROL BRAIN REGIONS}

A number of regions in the human brain have been implicated in a broad range of goal-directed behaviors (e.g., Posner and Petersen, 1990; Cabeza and Nyberg, 2000; Corbetta and Shulman, 2002; Cole and Schneider, 2007; Duncan, 2010). These regions include parts of the dorsolateral prefrontal cortex (along the inferior frontal sulcus/middle frontal gyrus), parts of the insular cortex, regions along the precentral gyrus (going inferiorly to the posterior aspects of the inferior frontal gyrus, IFG), pre-supplementary and supplementary motor area, parts of the anterior cingulate, and regions in and around the intraparietal sulcus (Figure 2). This set of regions-with sometimes slightly differing inclusion criteria and/or subdivisions - is referred to in the literature by many names, including "task-positive network," 
"cognitive control network," "fronto-parietal attention network," and "multiple-demand (MD) system." Following Duncan (2006, 2010), I will use the term "multiple-demand (MD) system" throughout the paper, but none of the arguments in section Narrowing Down the Hypothesis Space for the Relationship between Language Processing Mechanisms and Cognitive Control Mechanisms hinge on the details of any particular proposal about these regions.

In brain imaging investigations, difficulty contrasts across many manipulations have been shown to activate the MD system. For example, Duncan and Owen (2000; also Duncan, 2006) performed a meta-analysis of activation peaks from neuroimaging studies that manipulated (i) the number of items held in memory (more vs. fewer items), (ii) the duration of holding information in memory (long vs. short), (iii) inhibitory demands (high vs. low), (iv) task novelty (new vs. practiced tasks), and (v) perceptual difficulty (difficult to perceive vs. easy to perceive). Across all of these manipulations, activations were observed in the frontal and parietal MD regions. More recently, Fedorenko et al. (2012, 2013; see also Wojciulik and Kanwisher, 1999; Stiers et al., 2010) provided evidence for overlap among diverse demanding tasks at the single-subject level, ruling out the possibility that the overlapping regions that emerged in the earlier meta-analyses were simply an artifact of spatial averaging across studies (e.g., NietoCastañon and Fedorenko, 2012). Furthermore, a set of brain regions that very much resembles the MD system also emerges in the resting-state correlation data (e.g., Power et al., 2011).

Even stronger evidence of domain-generality comes from single-cell recording studies in non-human primates, which have shown that many neurons in the frontal lobes exhibit substantial flexibility, varying their response properties according to task demands ( e.g., Freedman et al., 2001; Miller and Cohen, 2001; Duncan, 2001; Cromer et al., 2010). For example, Freedman et al. (2001) trained macaques to categorize visual stimuli according to one dimension (cats vs. dogs). Following training, a substantial proportion of frontal neurons responded categorically to the relevant dimension. However, after training on a new task that used the same stimuli but required attention to a different dimension

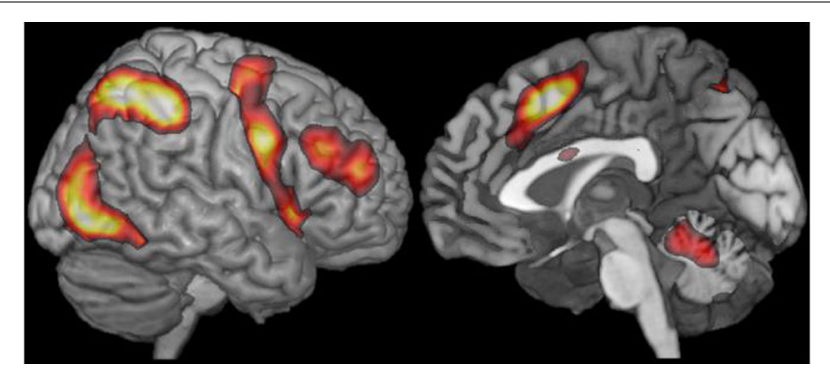

FIGURE 2 | From Fedorenko et al. (2013). A group-level representation of the multiple-demand activity based on average activity in left and right hemispheres. Following reflection of left hemisphere data to the right, 14 (7 tasks $\times 2$ hemispheres) $t$-maps were averaged, and the resulting map was thresholded at $t=1.5$. The tasks included: arithmetic addition, spatial working memory, verbal working memory, multi-source interference task (MSIT; Bush and Shin, 2006), a verbal version of MSIT, and Stroop (data from Fedorenko et al., 2013). of the stimuli, the same neurons that previously categorized stimuli into cats and dogs now showed categorical responses to the new task-relevant dimension (see also Roy et al., 2010). These and other results suggest that these frontal neurons adapt the information they code to fit current goals. Similar "adaptive coding" has been reported in the parietal cortex (Freedman and Assad, 2006).

How do MD regions support complex behaviors? As of now, this remains an open question. Some notions that have been prominent in the literature in the context of this system include attention (e.g., Posner and Petersen, 1990; Desimone and Duncan, 1995; Petersen and Posner, 2012), working memory (e.g., Goldman-Rakic, 1995), cognitive control (e.g., Miller and Cohen, 2001; Koechlin et al., 2003; Badre and D'Esposito, 2009), structure building/unification (e.g., Hagoort, 2005), timing and/or sequencing (e.g., Luria, 1966; Janata and Grafton, 2003; Fuster, 2008), attentional episodes in goal-directed behavior (Duncan, 2010), and conscious awareness (e.g., Dehaene and Changeux, 2011), among others. However, most existing proposals are generic enough to be compatible with a wide range of data patterns. Nonetheless, whatever the precise computations conducted by the MD regions turn out to be (see e.g., Rigotti et al., 2010 , for a proposal), this system is clearly of fundamental importance to humans, having been causally linked to fluid intelligence (Woolgar et al., 2010).

Given the spatial extent of the MD system and the cytoarchitectonic and connectomic diversity of its regions, many researchers have attempted to divide the MD system into subsystems (e.g., Botvinick et al., 2001, 2004; Koechlin et al., 2003; Dosenbach et al., 2007; Badre and D’Esposito, 2009), and/or to map specific components of the system onto particular mental functions [e.g., Aron et al. (2004) argued that the right IFG plays a critical role in cognitive control; Novick et al. (2005) made a similar argument for the left IFG]. Claims of dissociations among different executive functions have also been made based on behavioral work in healthy participants (individual differences and dual-task paradigms; e.g., Engle et al., 1999; Miyake et al., 2000) and in brain-damaged individuals (e.g., Vallar and Shallice, 1990; Hamilton and Martin, 2005). Correlations across regions in resting functional data have also been taken to argue for a fractionation of this system (Power et al., 2011). However, the broad similarity in functional responses among the MD brain regions is striking. As a result, for the purposes of this paper I consider the MD system as a whole, while allowing for the possibility that only a subset of this system may end up being important for language (see section The Hypotheses Space for the Relationship Between Language Processing Mechanisms and Cognitive Control Mechanisms).

\section{NEURAL SEPARABILITY OF HIGH-LEVEL LANGUAGE PROCESSING BRAIN REGIONS AND DOMAIN-GENERAL COGNITIVE CONTROL BRAIN REGIONS}

In recent work we investigated the relationship between high-level language processing brain regions and domain-general cognitive control brain regions (Fedorenko et al., 2011): we defined the regions of the language system using the sentences $>$ pseudoword lists contrast and then examined the responses of those functionally-defined regions of interest (fROIs) to a number of 
non-linguistic cognitive tasks that have been previously argued to share machinery with language processing. With the exception of one region (the LMFG fROI), language-responsive regions showed no response to arithmetic processing (see also Monti et al., 2012), working memory, or cognitive control tasks, like Stroop. However, the latter set of tasks robustly activated the MD system, whose subsets are located in close proximity to language-responsive regions, especially in the left frontal lobe (Fedorenko et al., 2012). Based on these results, we argued that language-responsive regions are functionally specialized for linguistic processing and require language input to drive them.

There are at least three possible objections to these results and their interpretation, and I attempt to briefly address them here. The first objection is as follows: perhaps some regions of the MD system do respond to sentences more than pseudoword lists-just like the language regions do-but the response is weaker and/or more variable across individuals. This would lead us to miss some language-responsive regions and thus to potentially miss overlap between responses to language and demanding cognitive tasks. In Fedorenko et al. (2011) we tried to ameliorate this concern by performing a whole-brain search - at liberal thresholds-for overlap between the responses to the language contrast (sentences $>$ pseudoword lists) and the hard > easy contrast in each of the non-linguistic demanding tasks. This search did not reveal much beyond what the basic analysis of the language-responsive fROIs had already shown: (i) language and verbal working memory showed overlap in the LMFG fROI; and (ii) there was a small region of overlap between language and two of the tasks (verbal working memory and Stroop) in posterior and dorsal-most part of the LIFG fROI, possibly due to the fact that MD regions abut the language-responsive parts of LIFG dorsally and posteriorly (see also Fedorenko et al., 2012), with spatial smoothing leading to the appearance of overlap (this possibility remains to be tested empirically using high-resolution scanning of the frontal cortex; cf. Schwarzlose et al., 2005). In Fedorenko et al. (2013; see also Supplementary Material), we report an analysis that shows that MD regions in fact respond to sentences and pseudowords in the opposite way from the language regions: they respond more strongly to linguistically degraded stimuli (pseudoword lists) than to linguistically meaningful and structured stimuli (sentences), suggesting that the language and the MD systems are spatially and functionally distinct.

The second objection is that perhaps the sentences we use in our "language localizer" task (Fedorenko et al., 2010) are too simple and don't contain a sufficient number of features that have been shown to cause comprehension difficulty, such as nonlocal dependencies (e.g., Gibson, 1998; Grodner and Gibson, 2005), lexical and/or structural ambiguity (e.g., Frazier, 1987; MacDonald et al., 1994), or low-frequency words or constructions (Preston, 1935; Forster and Chambers, 1973; Jurafsky, 1996; Levy, 2008). Maybe if more such features were present in the sentences, we would observe greater overlap between language and MD activations, which would manifest as (a) a greater response to MD tasks in the language regions, and/or (b) a greater response to sentences than pseudoword lists in the MD regions. In Supplementary Material, we show that even when we use naturalistic language materials (from the Brown corpus; Kucera and
Francis, 1967) that are representative of the kind of input that our language comprehension system receives, we find similar nonoverlap between the activations for the language localizer contrast and demanding cognitive tasks.

Finally, the third objection is as follows: given that (a) we typically use a memory probe task in our language localizer (where after each sentence or sequence of pseudowords participants have to decide whether a probe word/pseudoword appeared in the preceding stimulus; Fedorenko et al., 2010), and (b) the memory probe task is more difficult in the control condition (pseudoword lists) than in the sentences condition, we may be biasing ourselves against finding overlap with demanding tasks because, by design, we are excluding regions that respond to general cognitive effort. To investigate this possibility, we compared responses to a demanding task (spatial working memory) in fROIs defined by two different versions of the language localizer (with vs. without the memory probe task; see Supplementary Material). Across both versions of the localizer, we found little or no response to the conditions of the spatial working memory task in the language fROIs, similar to what we originally reported in Fedorenko et al. (2011). This result is not surprising given the similarity in the topographies of activations for different versions of the language localizer (see Figure 1).

In summary, regions of the language system are spatially and functionally distinct from the domain-general MD system. In contrast to the language regions, the MD regions respond at least as much, or more, during the processing of unconnected meaningless elements (pseudowords) as during the processing of sentences, including naturally occurring ones. The most important implication of the spatial segregation between the language system and the MD system is that we need to distinguish between the two in characterizing their roles in language comprehension/production, because the computations they perform are likely to be different given their different response profiles. This is especially important in the left frontal lobe, where subsets of each system reside side-by-side within Broca's area (Fedorenko et al., 2012).

Before proceeding to the next section, two conceptual issues that sometimes get conflated in the literature are important to clarify. First, functionally specialized circuits (e.g., brain regions that selectively respond to linguistic input) need not be encapsulated (see e.g., Coltheart, 1999; Barrett and Kurzban, 2006 for discussion). Our brain is highly interconnected, although some brain regions have been argued to be more globally connected than others, serving as "hubs" (e.g., Achard et al., 2006; Sporns et al., 2007; Hagmann et al., 2008; Heuvel et al., 2008; Buckner et al., 2009; Cole et al., 2010). Given this interconnectivity, the notion of encapsulation is a priori not plausible as applied to language-responsive or any other brain regions. Moreover, apart from perhaps quite obvious interactions between high-level language processing regions and sensory (visual and auditory) regions as well as motor regions that support articulation or control eye-movements during reading, abundant evidence shows that the language system interacts with many higher-level cognitive systems, including the visual system (e.g., Myachykov and Posner, 2005; Ferreira and Tanenhaus, 2007), the system that supports social cognition (e.g., Brennan et al., 2010; Fitch et al., 
2010), and the domain-general working memory/cognitive control mechanisms (as will be discussed in section Narrowing Down the Hypothesis Space for the Relationship between Language Processing Mechanisms and Cognitive Control Mechanisms). So, although lack of encapsulation of the language system has sometimes been offered as an argument against domain-specificity of language (e.g., Blumstein and Amso, 2013), this argument does not hold because functional specialization is perfectly compatible with interactions between specialized mechanisms and the rest of the mind and brain (see also Fedorenko and Thompson-Schill, 2014).

And second, specialized circuits need not be innate (see e.g., Karmiloff-Smith, 1992; Elman et al., 1996 for discussion). Functional specialization can develop via extensive experience with particular stimuli. One notable example is the visual wordform area, vWFA, a visual region that responds selectively to letters in one's native script (e.g., Baker et al., 2007). Recent work with non-human primates also suggests that specialized circuits can develop via an experiential route (e.g., Srihasam et al., 2011). Given that language is one of the most frequent and salient stimuli in our environment from birth (or even before) and throughout our lifetimes, it is computationally efficient to develop machinery that is specialized for processing linguistic stimuli.

\section{THE HYPOTHESES SPACE FOR THE RELATIONSHIP BETWEEN LANGUAGE PROCESSING MECHANISMS AND COGNITIVE CONTROL MECHANISMS}

I focus on two inter-related aspects of the relationship between language processing mechanisms and cognitive control mechanisms.

First, how frequently do cognitive control mechanisms get engaged when we understand language? The logical possibilities here range from never to always. Previous evidence (to be discussed in section Narrowing Down the Hypothesis Space for the Relationship between Language Processing Mechanisms and Cognitive Control Mechanisms) has established that cognitive control mechanisms are sometimes engaged when we understand language, thus ruling out the "never" possibility. However, this still leaves us with a large space of possibilities, from engagement only in rare circumstances, to continual engagement whenever we understand language.

And second, is the engagement of cognitive control mechanisms necessary for understanding language? The at least occasional engagement of domain-general cognitive control mechanisms in language comprehension is compatible with, but does not entail, their necessity for comprehension.

My working definition of "necessary" is as follows: A brain region is necessary for a mental process $x$, if and only if $x$ cannot proceed (or proceeds with substantially reduced speed or accuracy) once the relevant brain region is damaged or removed ${ }^{5}$. So,

${ }^{5} \mathrm{I}$ here have in mind mature adult brains. It is well-known that removal of extensive portions of the brain, including whole hemispheres, in early childhood has few, if any, consequences for cognitive functioning (e.g., Mariotti et al., 1998; Van Lancker-Sidtis, 2004). Similarly, gradual brain deformation due to early-onset disorders like hydrocephalus also often leaves the person largely cognitively intact. These kinds of evidence suggest a high degree of brain plasticity early in development. a brain region is necessary for language comprehension if and only if linguistic input cannot be interpreted without this region. (Note that the necessary role of a brain region in a mental process is orthogonal to its functional specialization for that mental process. A brain region may be necessary for processing a particular class of stimuli and yet be engaged in processing a wide range of stimuli. For example, primary visual cortex is critical for face perception and yet it is engaged during the processing of any visual stimulus).

At least four possibilities exist with respect to the question of whether cognitive control mechanisms-that I assume to be implemented in the MD system, as discussed above-are critical for understanding language:

(1) Every component of the MD system is necessary for language comprehension.

If this were the case, then disrupting any part of the MD system would lead to severe difficulties in understanding language.

(2) Only some components of the MD system (e.g., perhaps only the $M D$ regions in the left hemisphere; Duncan, 2001) are necessary for language comprehension.

According to this possibility, disrupting some but not other parts of the MD system would lead to severe comprehension problems.

(3) The MD system as a whole is necessary for language comprehension, but no individual component is critical (i.e., the "responsibilities" are distributed across the system).

This possibility is inspired by the findings of Woolgar et al. (2010), who demonstrated a linear relationship between the amount of damage to the MD system and the intelligence quotient (IQ), such that the more extensive the damage the lower the IQ. A similar relationship may hold between the MD system and language comprehension: disrupting any individual component may only slightly affect comprehension abilities, but disrupting increasingly larger portions of the MD system would eventually lead to one's inability to comprehend linguistic input. This general idea is reminiscent of Lashley's (1929) notion of equipotentiality, which may to some degree characterize the MD system.

(4) No part of the MD system is critical for language comprehension.

If this were the case, then disrupting any or all of the MD system would have little or no effect on language comprehension.

These possibilities are difficult to tease apart, and at present we can only rule out the first possibility and some versions of the third possibility. In particular, suppressing the activity of the non-language-dominant hemisphere, including of course the MD regions in that hemisphere, during the intracarotid sodium amobarbital procedure (i.e., the "Wada test"; Wada, 1949), does not appear to greatly affect linguistic abilities (e.g., Rasmussen and Milner, 1977). Of course, it is important to keep in mind that the kinds of language tasks used during the Wada procedure vary substantially across labs and perhaps do not include the most 
sophisticated tasks currently available for assessing linguistic abilities. Nevertheless, the fact that patients with an anesthetized non-language-dominant (typically, right) hemisphere can understand spoken commands, name pictures, read sentences and repeat phrases, suggests that the core linguistic abilities are preserved. Similarly, removal of the right hemisphere in adulthood impairs many cognitive abilities (e.g., visuo-spatial functions) but leaves linguistic processing largely intact (e.g., Basser, 1962; Searleman, 1977). These results therefore suggest that the MD regions in the non-language-dominant hemisphere are not necessary for linguistic processing. They further constrain the third possibility such that only the language-dominant-hemisphere $M D$ regions can be part of the system that is critical for language comprehension. Below I discuss the evidence for why they may or may not be.

\section{NARROWING DOWN THE HYPOTHESIS SPACE FOR THE RELATIONSHIP BETWEEN LANGUAGE PROCESSING MECHANISMS AND COGNITIVE CONTROL MECHANISMS}

That domain-general cognitive control mechanisms are sometimes engaged during language comprehension is not under debate (see e.g., Novick et al., 2010, for a recent review of the literature). Over the years, abundant evidence has been provided for the connection between working memory and cognitive control resources on the one hand, and language comprehension, on the other hand. This evidence comes from both (a) behavioral studies in healthy and brain-damaged individuals, and (b) brain imaging investigations. For example, in behavioral work, super-additive processing difficulty has been observed in dualtask paradigms that include a language comprehension task and a secondary demanding non-linguistic task (e.g., Wanner and Maratsos, 1978; Waters et al., 1987; Just and Carpenter, 1992; Waters and Caplan, 1996; Gordon et al., 2002; Fedorenko et al., 2006, 2007); associations between language comprehension and executive function abilities have been reported in individualdifferences investigations (e.g., Baddeley et al., 1985; King and Just, 1991; Gernsbacher, 1993; Daneman and Merikle, 1996; De Beni and Palladino, 2000; Seigneuric et al., 2000; Burton and Daneman, 2007; Carretti et al., 2009; Novick et al., 2009; Cragg and Nation, 2010; Khanna and Boland, 2010; Gibson and Fedorenko, 2011; McVay and Kane, 2012; Astheimer et al., 2014; cf. Caplan and Waters, 1999); and the depth of linguistic processing has been shown to be affected by top-down reader goals (e.g., Wotschack, 2009). Furthermore, one prominent class of syntactic complexity accounts explains across-construction variability in processing complexity in terms of differential working memory demands (e.g., Wanner and Maratsos, 1978; Gibson, 1998, 2000; Gordon et al., 2002; McElree et al., 2003; Lewis et al., 2006).

Similarly, numerous fMRI studies have reported activations during language comprehension tasks in the domain-general brain regions of the $\mathrm{MD}$ system, i.e., in the same brain regions that get modulated by working memory and cognitive control demands (e.g., Duncan and Owen, 2000). A wide range of language phenomena have been shown to produce such activations (often in addition to also activating the language regions). These include: non-local syntactic dependencies, especially in older populations (e.g., Peelle et al., 2010; see Kaan and Swaab, 2002;
Rogalsky and Hickok, 2011 for a discussion of syntactic complexity manipulations in terms of domain-general factors), ambiguous words or constructions (e.g., Rodd et al., 2005; Novais-Santos et al., 2007; January et al., 2009; McMillan et al., 2013), pronouns whose referents may not be clear from the context (e.g., McMillan et al., 2012), sentences that contain grammatical errors (e.g., Kuperberg et al., 2003; Nieuwland et al., 2012), speech presented under noisy conditions (e.g., Wild et al., 2012), etc.

One possible generalization-based on both behavioral and brain imaging evidence-is that domain-general mechanisms are recruited when difficulties arise in language comprehension, which can of course happen for many reasons. Given that difficulty manipulations across a wide range of cognitive tasks have been shown to produce activity in the regions of the MD system, perhaps the engagement of these circuits during comprehension difficulties in language is not too surprising. Nevertheless, this body of literature is important in that it convincingly establishes that the language interpretation system is not encapsulated (cf. Fodor, 1983) but rather can interact in a flexible way with domain-general working memory and cognitive control mechanisms.

Now, on to the two questions whose answers would help us better understand the precise nature of the relationship between language understanding and domain-general cognitive control mechanisms.

\section{HOW FREQUENTLY DO COGNITIVE CONTROL MECHANISMS GET ENGAGED WHEN WE UNDERSTAND LANGUAGE?}

Given that most evidence for the engagement of cognitive control mechanisms in language comprehension comes from cases where language processing is effortful, let us consider how often comprehension difficulties arise in naturalistic linguistic exchanges. For example, how frequently do we encounter ambiguous words whose meaning is not fully constrained by the preceding context? What about non-local dependencies between words? Or cases where we have to rely on a single cue (e.g., word order) to interpret the propositional content of an utterance? Although it is difficult to quantify the proportion of such phenomena in typical linguistic exchanges, corpus analyses suggest that linguistic phenomena that many studies in the field of sentence processing have focused on may not be very common. For example, Piantadosi et al. (2012) demonstrated that ambiguous words are typically used in contexts that strongly favor the relevant meaning. Collins (1996; also Temperley, 2007) has shown that most linguistic dependencies are between adjacent elements (see also Frank et al., 2012). And Roland et al. (2007) showed that object-extracted relative clauses with two full animate noun phrases (e.g., "The senator that the reporter attacked was tall")—-perhaps the most frequently investigated construction in the study of syntactic processing-rarely occur.

Indeed, typical linguistic input abounds with cues to meaning, including lexical information, syntactic information, plausibility/world knowledge information, linguistic and non-linguistic (e.g., visual, social) context, and prosodic/punctuation cues. During the last 30 years, research in the field of sentence processing has established that comprehenders rationally use all the information sources available in the input to derive an 
interpretation of an input string (e.g., Trueswell and Tanenhaus, 1994; Gibson and Pearlmutter, 1998). It is therefore possible that the focus on controlled manipulations that alter the statistics of the human language has led us to overestimate the importance of domain-general working memory and cognitive control mechanisms in understanding language.

However, comprehension difficulty is of course not categorical. Instead, it varies continuously as we perceive linguistic input and is determined by some combination of (i) how expected the input is from the preceding context, and (ii) how much memory is required for integrating the incoming element into the evolving structure/meaning representation (e.g., Demberg and Keller, 2008; Levy, 2008; Gibson et al., 2014; Levy et al., 2014). The question then becomes: What does it take for the domain-general mechanisms to "kick in" during language understanding? In particular, is the MD system (or some subset of it) always active when we perceive language? Does this system get engaged only when we pay attention to the linguistic input, i.e., when the information in the linguistic signal is somehow relevant to us, or maybe only when some threshold of comprehension difficulty has been reached? Or perhaps we turn to the domain-general mechanisms only in rare cases, as a last resort, when the language system "gives up" on interpretation? Now that we have ample evidence that domain-general mechanisms do sometimes get engaged during language comprehension tasks, we can perhaps focus on understanding the precise conditions under which these mechanisms are recruited, to narrow down these various possibilities.

\section{ARE COGNITIVE CONTROL MECHANISMS NECESSARY FOR UNDERSTANDING LANGUAGE?}

What does the engagement of cognitive control brain regions reflect? Is this engagement functionally important, so that without a properly functioning MD system (or some subset thereof) language interpretation would be severely hampered or impossible? Or is the activation of the MD system simply an "echo" of the effort experienced by the "core" language interpretation system?

To tackle these questions, we need methods that would allow us to examine the effects on language comprehension of inaccessibility of domain-general cognitive control mechanisms. As a result, most evidence from brain imaging investigations does not directly inform these questions. This is also true of much of behavioral evidence, although super-additive processing difficulty observed in dual-task paradigms discussed above does afford some degree of causal interpretation and suggests that taxing domain-general working memory resources can interfere with the processing of (at least syntactically complex) sentences (e.g., Gordon et al., 2002; Fedorenko et al., 2006, 2007). Most direct evidence, however, comes from investigations of individuals with impaired cognitive control abilities. Below I review some of this evidence in light of two alternative positions: cognitive control mechanisms are vs. are not necessary for language comprehension.

\section{Evidence for the necessity of cognitive control mechanisms for language comprehension}

A few studies have provided evidence of associations between difficulties with some aspects of language comprehension and non-linguistic working memory/cognitive control tasks in individuals with brain damage (e.g., Novick et al., 2009; Vuong and Martin, 2011), or with developmental disorders like specific language impairment (e.g., Montgomery, 2003). However, evidence from associations in neuropsychology is notoriously difficult to interpret (e.g., Whitehouse et al., 1978; Caramazza et al., 1982), especially given that domain-general MD regions often lie in close proximity to the regions of the language system (e.g., Fedorenko et al., 2012).

Although I have focused here on cognitive control/working memory, it is important to also consider the role of attention in language comprehension, given that attention is tightly linked to the MD system (e.g., Corbetta and Shulman, 2002; Duncan, 2006). The classic studies of speech perception in the unattended channel (e.g., Cherry, 1953; Broadbent, 1958; Treisman, 1964) showed-across many variations of a similar paradigm - that when presented with two auditory streams and asked to attend to one of the streams listeners are only able to extract minimal information from the unattended stream. Indeed, from mere introspection, we know that when we are not paying attentionwhether due to some external stimulus or an internally generated thought-we can "zone out" and miss, for example, a part of a lecture, or a paragraph in a book (see Reichle et al., 2010, for evidence that our eye movement patterns differentiate between the text fragments where we are reading for meaning vs. reading while thinking about something else; also Kaakinen and Hyönä, 2014). These early experimental findings and introspective observations suggest that some minimal amount of attention is necessary to understand language. So to the extent that attention is implemented in the MD system, some minimal MD activity may be required for language comprehension. (Whether this activity is linked to a particular component of the MD system remains to be determined).

\section{Evidence against the necessity of cognitive control mechanisms for language comprehension}

Perhaps the most compelling evidence comes from the developmental and aging literatures. In particular, the lifetime trajectories of executive and language abilities are different: our cognitive control abilities are slow-developing in childhood, not reaching full maturity until early adulthood (e.g., Kail, 1991a,b,c; Kail and Salthouse, 1994; Harnishfeger and Pope, 1996; Fischer et al., 1997; Munoz et al., 1998; Diamond, 2002; Luciana and Nelson, 2002; De Luca et al., 2003; Luna et al., 2004; Lyons-Warren et al., 2004; Zelazo et al., 2004; Luciana et al., 2005), and yet already at age 5 children can understand impressive amounts of linguistic input (e.g., Kuhl, 2004; Hoff, 2009). In fact, some have argued that the lack of mature cognitive control mechanisms is actually helpful for some aspects of language acquisition (e.g., Newport, 1990; cf. Rohde and Plaut, 1999; Chrysikou et al., 2011). Similarly, although our executive functions decay as we age, our language comprehension abilities remain intact (e.g., Wingfield and Grossman, 2006; Burke and Shafto, 2008), and some abilities (e.g., vocabulary knowledge) keep improving with age (e.g., Field and Gueldner, 2001; Park et al., 2002; Uttl, 2002; Verhaeghen, 2003; Ronnlund et al., 2005). On the extreme end are cases of agerelated dementia where some language comprehension abilities 
remain intact in spite of the steep decline in cognitive control and working memory (Schwartz et al., 1979; cf. Grossman et al., 1996; MacDonald et al., 2001).

Secondly, a number of developmental disorders are characterized by impairments in executive functions with a relative, though almost never complete, sparing of language comprehension abilities, including Turner syndrome (e.g., Money, 1964; Money and Alexander, 1966; Garron, 1970; Murphy, 2009), and select cases of Williams syndrome (e.g., Von Arnim and Engel, 1964; Bellugi et al., 1988, 2000; cf. Karmiloff-Smith, 2006; Mervis and Becerra, 2007) and Down's syndrome (e.g., Evans and Hampson, 1968; Ryan, 1975; Bloom and Lahey, 1978; Rosenberg, 1982; Yamada, 1990; Rondal, 1994, 1995; Anderson et al., 2001; De Luca and Leventer, 2008; cf. Graham and Graham, 1971; Wisniewski et al., 1988). These cases are complemented by rare cases of language savants, individuals with highly impaired general intelligence and allegedly superior linguistic abilities (e.g., Smith and Tsimpli, 1995; cf. Bates, 1997).

Finally, one other line of evidence is worth a brief mention even though it is at present highly controversial (e.g., Laureys et al., 2005). Several reports have suggested that some degree of high-level linguistic processing (e.g., semantic processing) can take place even in patients with severe disorders of consciousness (e.g., Kotchoubey et al., 2002, 2003, 2005; Neumann and Kotchoubey, 2004; Schiff et al., 2005). Given that conscious awareness has been linked to the brain regions of the MD system (e.g., Dehaene and Changeux, 2011), this evidence-if it withstands further evaluation - may be able to provide a strong argument against the need for domain-general cognitive control in at least some aspects of language understanding.

In summary, the evidence for whether cognitive control mechanisms are necessary for us to understand language is at present complex, and more work is clearly needed to answer this question conclusively. The ability to define MD regions functionally at the individual subject level (e.g., Fedorenko et al., 2013) opens to the door to TMS investigations targeting those regions and examining the effects of transient disruption on different aspects of language processing. Furthermore, methods like that pioneered by Woolgar et al. (2010) — where the amount of MD system damage is related to behavioral performance-might prove useful, although such investigations are complicated by the proximity of the MD system to the language system, and thus high probability of damage affecting both systems. In light of the discussion in section How Frequently do Cognitive Control Mechanisms Get Engaged When We Understand Language?, I hope that we-as a field-can expand the scope of the linguistic phenomena we consider when thinking about the role of cognitive control in language. In particular, instead of focusing on language in highly atypical circumstances (e.g., doubly-center-embedded structures or cases where a referent is non-existent), we may want to tackle the more basic question of whether cognitive control is necessary for successful comprehension in typical linguistic exchanges.

\section{SUMMARY AND CONCLUSIONS}

In this paper I have discussed the role of domain-general cognitive control in language comprehension. In recent work we have shown that brain regions that respond robustly to linguistic input are spatially distinct from brain regions that have been linked to working memory and cognitive control (Fedorenko et al., 2011, 2012). These findings suggest that the computations performed by these two sets of brain regions are likely distinct. However, this neural separability of language processing and domain-general cognitive control is compatible with some form of interaction between them, and even with the domain-general circuits being necessary for understanding linguistic input.

Although much evidence suggests that domain-general MD regions are sometimes engaged during language comprehension, it is at present unclear how often this happens, and thus how theoretically significant this engagement is. Moreover, previously reported dissociations between language comprehension abilities and working memory/cognitive control abilities suggest that domain-general mechanisms may not need to function properly for successful language comprehension to occur. However, more evidence is needed to conclusively answer the question of the necessity of cognitive control in language understanding.

The fact that domain-general cognitive control mechanisms may not be necessary for understanding language should not make these mechanisms uninteresting to language researchers, especially given that these mechanisms (a) are important in language production as discussed at the beginning of the paper, and (b) have been implicated in preventing language loss in aging (e.g., Wingfield and Grossman, 2006) as well as in recovery from aphasia (e.g., Sharp et al., 2010). Understanding when and how cognitive control resources are deployed during language comprehension in mature or developing healthy brains may provide important constraints on theories of language acquisition and processing, as well as shed light onto the potential functions of the multiple demand system. For example, even if the MD system is not necessary for language comprehension, it may still turn out to be useful, by for example, making language comprehension faster and/or more efficient. A possible analogy is that of a bicycle: although we can get places without one, having one helps us get there faster. According to this view, the MD system is a flexible resource that may get allocated to a wide range of cognitive processes, including those supported by specialized machinery (like face perception or language), and has a beneficial effect on all of those processes. How exactly this facilitation may be implemented is important. For example, do the MD regions simply speed up the processing in the specialized regions by providing extra computational resources of a generic nature (a "workspace"; e.g., Dehaene and Changeux, 2011), or do they provide alternative routes for solving the problem at hand, be it recognizing a face or understanding a sentence?

One intriguing possibility with respect to language-and perhaps other domains - is that the MD system is used for predictive processing. In line with this idea, diminished predictive processing in language has been reported in both children (e.g., Garvey and Berninger, 1981), and aging individuals (e.g., Federmeier et al., 2002, 2010), i.e., groups with underdeveloped and deteriorating cognitive control mechanisms, respectively. There is no question that predictive processing is useful and can speed up the processing of incoming information (e.g., Levy, 2008; Smith and Levy, 2013). However, it is not required: language comprehension can proceed in a bottom-up way, as evidenced 
by the comprehension abilities of children, elderly individuals, and individuals with otherwise impaired cognitive control mechanisms. This idea-that language regions support a bottom-up language interpretation strategy and MD regions provide a topdown, predictive, strategy for language comprehension-deserves further evaluation.

To conclude, future work should (a) acknowledge that the "core" fronto-temporal language brain regions are spatially and functionally distinct from the domain-general fronto-parietal multiple demand system, and (b) focus on characterizing the circumstances under which domain-general cognitive control mechanisms get engaged during language comprehension, and the precise role of this engagement. Regardless of what the answers to these questions turn out to be, investigations of the relationship between the two systems - including the dynamics of their interaction (see also Fedorenko and Thompson-Schill, 2014)-are likely to inform both, theories of language and of domain-general cognition.

\section{ACKNOWLEDGMENTS}

For insightful comments on the earlier drafts, I am grateful to the two reviewers, John Duncan, Julie Fiez, Mike Frank, Nancy Kanwisher, Kyle Mahowald, Steve Piantadosi, and especially Ted Gibson, who read and commented on multiple drafts of the manuscript. For information on the Wada test, I thank David Caplan, Gus (Henry) Buchtel, and Robert Zatorre. For discussions about the relationship between functional specialization and innateness, I thank Jeff Elman, Jay McClelland and Steve Piantadosi. For help with developmental references, thanks to Melissa Kline. This work was supported by NICHD K99/R00 award HD-057522 to Evelina Fedorenko.

\section{SUPPLEMENTARY MATERIAL}

The Supplementary Material for this article can be found online at: http://www.frontiersin.org/journal/10.3389/fpsyg. 2014.00335/abstract

\section{REFERENCES}

Achard, S., Salvador, R., Whitcher, B., Suckling, J., and Bullmore, E. (2006). A resilient, low-frequency, small-world human brain functional network with highly connected association cortical hubs. J. Neurosci. 26, 63-72. doi: 10.1523/JNEUROSCI.3874-05.2006

Adank, P. (2012). The neural bases of difficult speech comprehension and speech production: two activation likelihood estimation (ALE) meta-analyses. Brain Lang. 122, 42-54. doi: 10.1016/j.bandl.2012.04.014

Alario, F. X., Chainay, H., Lehericy, S., and Cohen, L. (2006). The role of the supplementary motor area in word production. Brain Res. 1076, 129-143. doi: 10.1016/j.brainres.2005.11.104

Allendorfer, J. B., Lindsell, C. J., Siegel, M., Banks, C. L., Vannest, J., Holland, S. K., et al. (2012). Females and males are highly similar in language performance and cortical activation patterns during verb generation. Cortex 48, 1218-1233. doi: 10.1016/j.cortex.2011.05.014

Alm, H., and Nilsson, L. (2001). The use of car phones and changes in driver behaviour. Int. J. Vehicle Des. 26, 4-11. doi: 10.1504/IJVD.2001.001926

Anderson, V. A., Anderson, P., Northan, E., Jacobs, R., and Catroppa, C. (2001). Development of executive functions through late childhood and adolescence in an Australian sample. Dev. Neuropsychol. 20, 385-406. doi: 10.1207/S15326942DN2001_5

Aron, A. R., Robbins, T. W., and Poldrack, R. A. (2004). Inhibition and the right inferior frontal cortex. Trends Cogn. Sci. 8, 170-177. doi: 10.1016/j.tics.2004. 02.010
Ash, S., McMillan, C., Gunawardena, D., Avants, B., Morgan, B., Khan, A., et al. (2010). Speech errors in progressive non-fluent aphasia. Brain Lang. 113, 13-20. doi: 10.1016/j.bandl.2009.12.001

Astheimer, L., Janus, M., Moreno, S., and Bialystok, E. (2014). Electrophysiological measures of attention during speech perception predict metalinguistic skills in children. Dev. Cogn. Neurosci. 7, 1-12. doi: 10.1016/j.dcn.2013.10.005

Baddeley, A., Logie, R., Nimmo-Smith, I., and Brereton, N. (1985). Components of fluent reading. J. Mem. Lang. 24, 119-131. doi: 10.1016/0749-596X(85)90019-1

Badre, D., and D'Esposito, M. (2009). Is the rostro-caudal axis of the frontal lobe hierarchical? Nat. Rev. Neurosci. 10, 659-669. doi: 10.1038/nrn2667

Baker, C. I., Liu, J., Wald, L. L., Kwong, K. K., Benner, T., and Kanwisher, N. (2007). Visual word processing and experiential origins of functional selectivity in human extrastriate cortex. Proc. Natl. Acad. Sci. U.S.A. 104, 9087-9092. doi: 10.1073/pnas.0703300104

Baldo, J. V., Wilkins, D. P., Ogar, J., Willock, S., and Dronkers, N. F. (2011). Role of the precentral gyrus of the insula in complex articulation. Cortex 47, 800-807. doi: 10.1016/j.cortex.2010.07.001

Barrett, H. C., and Kurzban, R. (2006). Modularity in cognition: framing the debate. Psychol. Rev. 113, 628-647. doi: 10.1037/0033-295X.113.3.628

Basho, S., Palmer, E. D., Rubio, M. A., Wulfeck, B., and Muller, R. A. (2007). Effects of generation mode in fMRI adaptations of semantic fluency: paced production and overt speech. Neuropsychologia 45, 1697-1706. doi: 10.1016/j.neuropsychologia.2007.01.007

Basser, L. S. (1962). Hemiplegia of early onset and the faculty of speech with special reference to the effects of hemispherectomy. Brain 85, 427-460. doi: 10.1093/brain/85.3.427

Bates, E. (1997). On language savants and the structure of the mind: a review of Neil Smith and Ianthi-Maria Tsimpli, the mind of a savant: language learning and modularity. Int. J. Bilingualism 1, 163-179.

Bates, E., Wilson, S. M., Saygin, A. P., Dick, F., Sereno, M. I., Knight, R. T., et al. (2003). Voxel-based lesion-symptom mapping. Nat. Neurosci. 6, 448-450. doi: 10.1038/nn 1050

Bavelier, D., Corina, D., Jezzard, P., Clark, V. P., Karni, A., Rauschecker, J., et al. (1998). Hemispheric specialization for english and american sign language: left invariance, right variablity. Neuroreport 9, 1537-1542. doi: 10.1097/00001756199805110-00054

Bedny, M., Pascual-Leone, A., Dodell-Feder, D., Fedorenko, E., and Saxe, R. (2011). Language processing in the occipital cortex of congenitally blind adults. Proc. Natl. Acad. Sci. U.S.A. 108, 4429-4434. doi: 10.1073/pnas.1014818108

Belin, P., Zatorre, R. J., Lafaille, P., Ahad, P., and Pike, B. (2000). Voice-selective areas in human auditory cortex. Nature 403, 309-312. doi: 10.1038/35002078

Bellugi, U., Lichtenberger, L., Jones, W., Lai, Z., and St. George, M. (2000). "The neurocognitive profile of Williams syndrome: a complex pattern of strengths and weaknesses," in Linking Cognitive Neuroscience and Molecular Genetics. Special Issue: Journal of Cognitive Neuroscience. Vol. 12, eds U. Bellugi and St. M. George (Cambridge, MA: MIT Press), 7-29. doi: 10.1162/089892900 561959

Bellugi, U., Marks, S., Bihrle, A., and Sabo, H. (1988). "Dissociation between language and cognitive functions in Williams syndrome," in Language Development in Exceptional Circumstances, eds E. Bishop and K. Mogford (Edinburgh: Churchill Livingstone), 177-189.

Bernstein, N. A. (1996). "On dexterity and its development," in Dexterity and Its Development, eds M. L. Latash and M. T. Turvey (Mahwah, NJ: Lawrence Erlbaum Associates), 3-44.

Binder, J. R., Desai, R. H., Graves, W. W., and Conant, L. L. (2009). Where is the semantic system? a critical review and meta-analysis of 120 functional neuroimaging studies. Cereb. Cortex 19, 2767-2796. doi: 10.1093/cercor/ bhp055

Binder, J. R., Frost, J. A., Hammeke, T. A., Bellgowan, P. S., Springer, J. A., Kaufman, J. N., et al. (2000). Human temporal lobe activation by speech and nonspeech sounds. Cereb. Cortex 10, 512-528. doi: 10.1093/cercor/10.5.512

Binder, J. R., Frost, J. A., Hammeke, T. A., Cox, R. W., Rao, S. M., and Prieto, T. (1997). Human brain language areas identified by functional MRI. J. Neurosci. $17,353-362$.

Bloom, L., and Lahey, M. (1978). Language Development and Language Disorders. New York, NY: Wiley.

Blumstein, S. E., and Amso, D. (2013). Dynamic functional organization of language: insights from functional neuroimaging. Perspect. Psychol. Sci. 8, 44-48. doi: $10.1177 / 1745691612469021$ 
Bohland, J. W., and Guenther, F. H. (2006). An fMRI investigation of syllable sequence production. Neuroimage 32, 821-841. doi: 10.1016/j.neuroimage. 2006.04.173

Botvinick, M., Braver, T., Barch, D., Carter, C., and Cohen, J. (2001). Conflict monitoring and cognitive control. Psychol. Rev. 108, 624-652. doi: 10.1037/0033295X.108.3.624

Botvinick, M., Cohen, J. D., and Carter, C. S. (2004). Conflict monitoring and anterior cingulate cortex: an update. Trends Cogn. Sci. 8, 539-546. doi: 10.1016/j.tics.2004.10.003

Braze, D., Mencl, W. E., Tabor, W., Pugh, K. R., Constable, R. T., Fulbright, R. K. et al. (2011). Unification of sentence processing via Ear and Eye: an fMRI Study. Cortex 47, 416-431. doi: 10.1016/j.cortex.2009.11.005

Brendel, B., Hertrich, I., Erb, M., Lindner, A., Riecker, A., Grodd, W., et al (2010). The contribution of mesiofrontal cortex (SMA) to the preparation and execution of repetitive syllable productions: an fMRI study. Neuroimage 50, 1219-1230. doi: 10.1016/j.neuroimage.2010.01.039

Brennan, S. E., Galati, A., and Kuhlen, A. (2010). "Two minds, one dialog: coordinating speaking and understanding," in Psychology of Learning and Motivation, Vol. 53, ed B. Ross (Burlington: Academic Press/Elsevier), 301-344.

Briellmann, R. S., Saling, M. M., Connell, A. B., Waites, A. B., Abbott, D. F., and Jackson, G. D. (2004). A high-field functional MRI study of quadri-lingual subjects. Brain Lang. 89, 531-542. doi: 10.1016/j.bandl.2004.01.008

Broadbent, D. (1958). Perception and Communication. London: Pergamon Press. doi: $10.1037 / 10037-000$

Broca, P. (1861). [Notes on the seat of the faculty of articulate language, followed by an observation of aphemia]. Bull. Soc. Anat. Paris 6, 330-357.

Buchweitz, A., Mason, R. A., Tomitch, L. M. B., and Just, M. (2009). Brain activation for reading and listening comprehension: an fMRI study of modality effects and individual differences in language comprehension. Psychol. Neurosci. 2, 111-123. doi: 10.3922/j.psns.2009.2.003

Buckner, R. L., Sepulcre, J., Talukdar, T., Krienen, F. M., Liu, H., Hedden, T., et al. (2009). Cortical hubs revealed by intrinsic functional connectivity: mapping, assessment of stability, and relation to Alzheimer's disease. J. Neurosci. 29, 1860-1873. doi: 10.1523/JNEUROSCI.5062-08.2009

Burke, D. M., and Shafto, M. A. (2008). "Language and aging," in The Handbook of Aging and Cognition, eds F. I. M. Craik and T. A. Salthouse (New York, NY: Psychology Press), 373-443.

Burton, C., and Daneman, M. (2007). Compensating for a limited working memory capacity during reading: evidence from eye movements. Read. Psychol. 28 163-186. doi: 10.1080/02702710601186407

Bush, G., and Shin, L. M. (2006). The multi-source interference task: an fMRI task that reliably activates the cingulo-frontal-parietal cognitive/attention network. Nat. Protoc. 1, 308-313. doi: 10.1038/nprot.2006.48

Cabeza, R., and Nyberg, L. (2000). Imaging cognition II: an empirical review of 275 PET and fMRI studies. J. Cogn. Neurosci. 12, 1-47. doi: 10.1162/089892900 51137585

Caplan, D., and Waters, G. S. (1999). Verbal working memory and sentence comprehension. Brain Behav. Sci. 22, 77-126. doi: 10.1017/S0140525X99001788

Caramazza, A., Berndt, R. S., and Brownell, H. H. (1982). The semantic deficit hypotheses: perceptual parsing and object classification by aphasic patients. Brain Lang. 15, 161-189. doi: 10.1016/0093-934X(82)90054-2

Carretti, B., Borella, E., Cornoldi, C., and De Beni, R. (2009). Role of working memory in explaining the performance of individuals with specific reading comprehension difficulties: a meta-analysis. Learn. Individ. Differ. 19, 246-251. doi: 10.1016/j.lindif.2008.10.002

Catani, M., Jones, D. K. J., and Ffytche, D. H. (2005). Perisylvian language networks of the human brain. Ann. Neurol. 57, 8-16. doi: 10.1002/ana.20319

Chee, M. W., Buckner, R. L., O'Craven, K. M., Bergida, R., Rosen, B. R., and Savoy, R. L. (1999c). Auditory and visual word processing studied with fMRI. Hum. Brain Mapp. 7, 15-28. doi: 10.1002/(SICI)1097-0193(1999)7:1\%3C15::AIDHBM2\%3E3.3.CO;2-Y

Chee, M. W. L., Caplan, D., Soon, C. S., Sriram, N., Tan, E. W. L., Thiel, T., et al. (1999a). Processing of visually presented sentences in mandarin and english studied with fMRI. Neuron 23, 127-137. doi: 10.1016/S0896-6273(00)80759-X

Chee, M. W. L., Tan, E. W. L., and Thiel, T. (1999b). Mandarin and English single word processing studied with fMRI. J. Neurosci. 19, 3050-3056.

Chee, M. W., Soon, C. S., and Lee, H. L. (2003). Common and segregated neuronal networks for different languages revealed using functional magnetic resonance adaptation. J. Cogn. Neurosci. 15, 85-97. doi: 10.1162/089892903321107846
Cherry, E. C. (1953). Some experiments on the recognition of speech, with one and with two ears. J. Acoust. Soc. Am. 25, 975-979. doi: 10.1121/1.1907229

Christiansen, M. H., and Chater, N. (2008). Language as shaped by the brain. Behav. Brain Sci. 31, 489-509. doi: 10.1017/S0140525X08004998

Chrysikou, E. G., Novick, J. M., Trueswell, J. C., and Thompson-Schill, S. L. (2011). The other side of cognitive control: can a lack of cognitive control benefit language and cognition? Top. Cogn. Sci. 3, 253-256. doi: 10.1111/j.17568765.2011.01137.x

Coelho, C., Lê, K., Mozeiko, J., Krueger, F., and Grafman, J. (2012). Discourse production following injury to the dorsolateral prefrontal cortex. Neuropsychologia 50, 3564-3572. doi: 10.1016/j.neuropsychologia.2012.09.005

Cole, M. W., Pathak, S., and Schneider, W. (2010). Identifying the brain's most globally connected regions. Neuroimage 49, 3132-3148. doi: 10.1016/j.neuroimage.2009.11.001

Cole, M. W., and Schneider, W. (2007). The cognitive control network: integrated cortical regions with dissociable functions. Neuroimage 37, 343-360. doi: 10.1016/j.neuroimage.2007.03.071

Collins, M. (1996). "A new statistical parser based on bigram lexical dependencies," in Proceedings of the 34th Annual Meeting of the ACL (Santa Cruz, CA). doi: $10.3115 / 981863.981888$

Coltheart, M. (1999). Modularity and cognition. Trends Cogn. Sci. 3, 115-120. doi: 10.1016/S1364-6613(99)01289-9

Corbetta, M., and Shulman, G. L. (2002). Control of goal-directed and stimulus-driven attention in the brain. Nat. Rev. Neurosci. 3, 201-215. doi: $10.1038 / \mathrm{nrn} 755$

Cragg, L., and Nation, K. (2010). Language and the development of cognitive control. Topics Cogn. Sci. 2, 631-642. doi: 10.1111/j.1756-8765.2009. 01080.x

Cromer, J. A., Roy, J. E., and Miller, E. K. (2010). Representation of multiple, independent categories in the primate prefrontal cortex. Neuron 66, 796-807. doi: 10.1016/j.neuron.2010.05.005

Culham, J. C., and Valyear, K. F. (2006). Human parietal cortex in action. Curr. Opin. Neurobiol. 16, 205-212. doi: 10.1016/j.conb.2006.03.005

Damasio, A. (1992). Aphasia. N. Engl. J. Med. 326, 531-539. doi: 10.1056/NEJM 199202203260806

Daneman, M., and Merikle, P. M. (1996). Working memory and language comprehension: a meta-analysis. Psychon. Bull. Rev. 3, 422-433. doi: 10.3758/BF03214546

Dax, M. (1863). Observations tendant à prouver la coïncidence constante des dérangements de la parole avec une lésion de l'hémisphère gauche du cerveau. Comptes rendus de l'Académie des Sciences 56, 536 (written and submitted in 1836).

De Beni, R., and Palladino, P. (2000). Intrusion errors in working memory tasks. are they related to reading comprehension ability? Learn. Individ. Dif. 12, 131-143. doi: 10.1016/S1041-6080(01)00033-4

Dehaene, S., and Changeux, J. P. (2011). Experimental and theoretical approaches to conscious processing. Neuron 70, 200-227. doi: 10.1016/j.neuron.2011. 03.018

Delnooz, C. C., Helmich, R. C., Medendorp, W. P., Van de Warrenburg, B. P. and Toni, I. (2013). Writer's cramp: Increased dorsal premotor activity during intended writing. Hum. Brain Mapp. 34, 613-625. doi: 10.1002/hbm. 21464

De Luca, C. R., and Leventer, R. J. (2008). "Developmental trajectories of executive functions across the lifespan," in Executive Functions and the Frontal Lobes: A Lifespan Perspective, eds V. Anderson, R. Jacobs, and P. J. Anderson (New York, NY: Taylor and Francis), 3-21.

De Luca, C. R., Wood, S. J., Anderson, V., Buchanan, J. A., Proffitt, T., Mahony, K., et al. (2003). Normative data from CANTAB: development of executive function over the lifespan. J. Clin. Exp. Neuropsychol. 25, 242-254. doi: 10.1076/jicen.25.2.242.13639

Demberg, V., and Keller, F. (2008). Data from eye-tracking corpora as evidence for theories of syntactic processing complexity. Cognition 109, 193-210. doi: 10.1016/j.cognition.2008.07.008

den Ouden, D. B., Fix, S., Parrish, T. B., and Thompson, C. K. (2009). Argument structure effects in action verb naming in static and dynamic conditions. J. Neurolinguistics 22, 196-215. doi: 10.1016/j.jneuroling.2008.10.004

Desimone, R., and Duncan, J. (1995). Neural mechanisms of selective attention. Annu. Rev. Neurosci. 18, 193-222. doi: 10.1146/annurev.ne.18.030195. 001205 
DeWitt, I., and Rauschecker, J. P. (2013). Wernicke's area revisited: parallel streams and word processing. Brain Lang. 127, 181-191. doi: 10.1016/j.bandl.2013. 09.014

Diamond, A. (2002). "Normal development of prefrontal cortex from birth to young adulthood: cognitive functions, anatomy, and biochemistry," in Principles of Frontal Lobe Function eds D. T. Stuss and R. T. Knight (London: Oxford University Press), 466-503. doi: 10.1093/acprof:oso/9780195134971. 003.0029

Diaz, M. T., and McCarthy, G. (2009). A comparison of brain activity evoked by single content and function words: an fMRI investigation of implicit word processing. Brain Res. 1282, 38-49. doi: 10.1016/j.brainres.2009.05.043

Dickerson, B. C. (2011). Quantitating severity and progression in primary progressive aphasia. J. Mol. Neurosci. 45, 618-628. doi: 10.1007/s12031-011-9534-2

Dosenbach, N. U. F., Fair, D. A., Miezin, F. M., Cohen, A. L., Wenger, K. K., Dosenbach, R. A. T., et al. (2007). Distinct brain networks for adaptive and stable task control in humans. Proc. Natl. Acad. Sci. U.S.A. 104, 11073-11078. doi 10.1073/pnas.0704320104

Duncan, J. (2001). An adaptive coding model of neural function in prefrontal cortex. Nat. Rev. Neurosci. 2, 820-829. doi: 10.1038/35097575

Duncan, J. (2006). Brain mechanisms of attention. Q. J. Exp. Psychol. 59, 2-27. doi: $10.1080 / 17470210500260674$

Duncan, J. (2010). The multiple-demand (MD) system of the primate brain: mental programs for intelligent behaviour. Trends Cogn. Sci. 14, 172-179. doi 10.1016/j.tics.2010.01.004

Duncan, J., and Owen, A. M. (2000). Common regions of the human frontal lobe recruited by diverse cognitive demands. Trends Neurosci. 23, 475-483. doi: 10.1016/S0166-2236(00)01633-7

Eickhoff, S. B., Heim, S., Zilles, K., and Amunts, K. (2009). A systems perspective on the effective connectivity of overt speech production. Philos. Transact. A Math. Phys. Eng. Sci. 367, 2399-2421. doi: 10.1098/rsta.2008.0287

Elman, J. L., Bates, E. A., Johnson, M. H., Karmiloff-Smith, A., Parisi, D., and Plunkett, K. (1996). Rethinking Innateness: A Connectionist Perspective on Development. Cambridge, MA: MIT Press.

Endo, Y., Saito, Y., Otsuki, T., Takahashi, A., Nakata, Y., Okada, K., et al. (2013). Persistent verbal and behavioral deficits after resection of the left supplementary motor area in epilepsy surgery. Brain Dev. 36, 74-79. doi: 10.1016/j.braindev. 2013.01.002

Engle, R. W., Tuholski, S. W., Laughlin, J. E., and Conway, A. R. A. (1999). Working memory, short-term memory and general fluid intelligence: a latent variable approach. J. Exp. Psychol. Gen. 128, 309-331. doi: 10.1037/0096-3445.128. 3.309

Evans, D., and Hampson, M. (1968). The language of mongols. Br. J. Disord. Commun. 3, 171-181. doi: 10.3109/13682826809011457

Federmeier, K. D., Kutas, M., and Schul, R. (2010). Age-related and individual differences in the use of prediction during language comprehension. Brain Lang. 115, 149-161. doi: 10.1016/j.bandl.2010.07.006

Federmeier, K. D., McLennan, D. B., De Ochoa, E., and Kutas, M. (2002). The impact of semantic memory organization and sentence context information on spoken language processing by younger and older adults: an ERP study. Psychophysiology 39, 133-146. doi: 10.1017/S0048577202001373

Fedorenko, E., Behr, M., and Kanwisher, N. (2011). Functional specificity for highlevel linguistic processing in the human brain. Proc. Nati. Acad. Sci. U.S.A. 108 , 16428-16433. doi: 10.1073/pnas.1112937108

Fedorenko, E., Duncan, J., and Kanwisher, N. (2012). Language-selective and domain-general regions lie side by side within Broca's area. Curr. Biol. 22, 2059-2062. doi: 10.1016/j.cub.2012.09.011

Fedorenko, E., Duncan, J., and Kanwisher, N. (2013). Broad domain generality in focal regions of frontal and parietal cortex. Proc. Nati. Acad. Sci. U.S.A. 110, 16616-16621. doi: 10.1073/pnas.1315235110

Fedorenko, E., Gibson, E., and Rohde, D. (2006). The nature of working memory capacity in sentence comprehension: evidence against domain-specific resources. J. Mem. Lang. 54, 541-553. doi: 10.1016/j.jml.2005.12.006

Fedorenko, E., Gibson, E., and Rohde, D. (2007). The nature of working memory in linguistic, arithmetic and spatial integration processes. J. Mem. Lang. 56, 246-269. doi: 10.1016/j.jml.2006.06.007

Fedorenko, E., Hsieh, P.-J., Nieto-Castañon, A., Whitfield-Gabrieli, S., and Kanwisher, N. (2010). A new method for fMRI investigations of language: defining ROIs functionally in individual subjects. J. Neurophysiol. 104, 1177-1194. doi: 10.1152/jn.00032.2010
Fedorenko, E., and Kanwisher, N. (2011). Some regions within Broca's area do respond more strongly to sentences than to linguistically degraded stimuli: a comment on Rogalsky Hickok (2010). J. Cogn. Neurosci. 23, 2632-2635. doi: 10.1162/jocn_a_00043

Fedorenko, E., and Thompson-Schill, S. (2014). Reworking the language network. Trends Cogn. Sci. 18, 120-126. doi: 10.1016/j.tics.2013.12.006

Ferreira, F., and Tanenhaus, M. K. (2007). Introduction to special issue on language-vision interactions. J. Mem. Lang. 57, 455-459. doi: 10.1016/j.jml. 2007.08.002

Ferstl, E. C., and von Cramon, D. Y. (2001). The role of coherence and cohesion in text comprehension: an event-related fMRI study. Brain Res. Cogn. Brain Res. 11, 325-340. doi: 10.1016/S0926-6410(01)00007-6

Field, D., and Gueldner, S. H. (2001). The oldest-old: how do they differ from the old-old? J. Gerontol. Nurs. 27, 20-27.

Fischer, B., Biscaldi, M., and Gezeck, S. (1997). On the development of voluntary and reflexive components in human saccade generation. Brain Res. 754 285-297. doi: 10.1016/S0006-8993(97)00094-2

Fitch, W. T., Huber, L., and Bugnyar, T. (2010). Social cognition and the evolution of language: constructing cognitive phylogenies. Neuron 65, 795-814. doi: 10.1016/j.neuron.2010.03.011

Fodor, J. (1983). Modularity of Mind. Cambridge, MA: MIT Press.

Forster, K. I., and Chambers, I. M. (1973). Lexical access and naming time. J. Verbal Learn. Verbal Behav. 12, 627-635. doi: 10.1016/S0022-5371(73) $80042-8$

Fox, M. D., and Raichle, M. E. (2007). Spontaneous fluctuations in brain activity observed with functional magnetic resonance imaging. Nat. Rev. Neurosci. 8, 700-711. doi: 10.1038/nrn2201

Frank, S., Bod, R., and Christiansen, M. (2012). How hierarchical is language use? Proc. R. Soc. B 297, 4522-4531. doi: 10.1098/rspb.2012.1741

Frazier, L. (1987). "Sentence processing: a tutorial review," in Attention and Performance XII, ed M. Coltheart (Hillsdale, NJ: Erlbaum), 559-585.

Freedman, D. J., and Assad, J. A. (2006). Experience-dependent representation of visual categories in parietal cortex. Nature 443, 85-88. doi: 10.1038/nature 05078

Freedman, D. J., Riesenhuber, M., Poggio, T., and Miller, E. K. (2001) Categorical representation of visual stimuli in the primate prefrontal cortex. Science 291, 312-316. doi: 10.1126/science.291.5502.312

Frost, J. A., Binder, J. R., Springer, J. A., Hammeke, T. A., Bellgowan, P. S., Roa, S. M. et al. (1999). Language processing is strongly left lateralized in both sexes: evidence from fMRI. Brain 122, 199-208. doi: 10.1093/brain/122.2.199

Fuster, J. M. (2008). The Prefrontal Cortex, Fourth Edition. London: Academic Press.

Garron, D. C. (1970). Sex-linked recessive inheritance of spatial and numerical abilities, and Turner's syndrome. Psychol. Rev. 77, 147-152. doi: 10.1037/ h0028714

Garvey, C., and Berninger, G. (1981). Timing and turn-taking in children's conversations. Discourse Process. 4, 27-57. doi: 10.1080/01638538109544505

Geranmayeh, F., Brownsett, S. L., Leech, R., Beckmann, C. F., Woodhead, Z., and Wise, R. J. (2012). The contribution of the inferior parietal cortex to spoken language production. Brain Lang. 121, 47-57. doi: 10.1016/j.bandl.2012. 02.005

Gernsbacher, M. A. (1993). Less skilled readers have less efficient suppression mechanisms. Psychol. Sci. 4, 294-298. doi: 10.1111/j.1467-9280.1993.tb00567.x

Geschwind, N. (1970). The organization of language and the brain. Science 170, 940-944. doi: 10.1126/science.170.3961.940

Gibson, E. (1998). Linguistic complexity: locality of syntactic dependencies. Cognition 68, 1-76. doi: 10.1016/S0010-0277(98)00034-1

Gibson, E. (2000). "The dependency locality theory: a distance-based theory of linguistic complexity," in Image, Language, Brain. eds Y. Miyashita, A. Marantz, and W. O'Neil (Cambridge, MA: MIT Press), 95-126.

Gibson, E., and Fedorenko, E. (2011). The Domain-Generality of Working Memory Resources for Language. Paris: Poster presented at the AMLaP conference.

Gibson, E., and Pearlmutter, N. (1998). Constraints on sentence comprehension. Trends Cogn. Sci. 2, 262-268. doi: 10.1016/S1364-6613(98)01187-5

Gibson, E., Tily, H., and Fedorenko, E. (2014). "The processing complexity of English relative clauses," in Language Down the Garden Path: The Cognitive and Biological Basis for Linguistic Structure. eds M. Sanz, I. Laka, and Tanenhaus (New York, NY: Oxford University Press), 149-173.

Goldman-Rakic, P. S. (1995). Cellular basis of working memory. Neuron 14, 477-485. doi: 10.1016/0896-6273(95)90304-6 
Gordon, P. C., Hendrick, R., and Levine, W. H. (2002). Memory load interference in syntactic processing. Psychol. Sci. 13, 425-430. doi: 10.1111/1467-9280. 00475

Gorno-Tempini, M. L., Dronkers, N. F., Rankin, K. P., Ogar, J. M., Phengrasamy, L., Rosen, H. J., et al. (2004). Cognition and anatomy in three variants of primary progressive aphasia. Ann. Neurol. 55, 335-346. doi: 10.1002/ana. 10825

Gorno-Tempini, M. L., Hillis, A. E., Weintraub, S., Kertesz, A., Mendez, M., Cappa, S. F., et al. (2011). Classification of primary progressive aphasia and its variants. Neurology 76, 1006-1014. doi: 10.1212/WNL.0b013e31821103e6

Grafton, S. T., and Hamilton, A. F. (2007). Evidence for a distributed hierarchy of action representation in the brain. Hum. Mov. Sci. 26, 590-616. doi: 10.1016/j.humov.2007.05.009

Graham, J., and Graham, L. (1971). Language behavior of the mentally retarded: Syntactic characteristics. Am. J. Ment. Defic. 75, 623-629.

Grande, M., Meffert, E., Schoenberger, E., Jung, S., Frauenrath, T., Huber, W. et al. (2012). From a concept to a word in a syntactically complete sentence: an fMRI study on spontaneous language production in an overt picture description task. Neuroimage 61, 702-714. doi: 10.1016/j.neuroimage.2012. 03.087

Grodner, D., and Gibson, E. (2005). Consequences of the serial nature of linguistic input. Cogn. Sci. 29, 261-290. doi: 10.1207/s15516709 $\operatorname{cog} 0000 \_7$

Grossman, M., and Ash, S. (2003). Primary progressive aphasia: a review. Neurocase 10, 3-18. doi: 10.1080/13554790490960440

Grossman, M., D’Esposito, M., Hughes, E., Onishi, K., Biassou, N., White-Devine, T., et al. (1996). Language comprehension profiles in Alzheimer's disease, multiinfarct dementia, and frontotemporal degeneration. Neurology 47, 183-189. doi: 10.1212/WNL.47.1.183

Hagmann, P., Cammoun, L., Gigandet, X., Meuli, R., Honey, C. J., Wedeen, V. J., et al. (2008). Mapping the structural core of human cerebral cortex. PLoS Biol. 6:e159. doi: 10.1371/journal.pbio.0060159

Hagoort, P. (2005). On Broca, brain and binding: a new framework. Trends Cogn. Sci. 9, 416-423. doi: 10.1016/j.tics.2005.07.004

Hagoort, P., Hald, L., Bastiaansen, M., and Petersson, K. M. (2004). Integration of word meaning and world knowledge in language comprehension. Science 304 438-441. doi: 10.1126/science.1095455

Haller, S., Radue, E. W., Erb, M., Grodd, W., and Kircher, T. (2005). Overt sentence production in event-related fMRI. Neuropsychologia 43, 807-814. doi: 10.1016/j.neuropsychologia.2004.09.007

Hamilton, A. C., and Martin, R. C. (2005). Dissociations among tasks involving inhibition: a single case study. Cogn. Affect. Behav. Neurosci. 5, 1-13. doi: 10.3758/CABN.5.1.1

Harnishfeger, K. K., and Pope, R. S. (1996). Intending to forget: the development of cognitive inhibition in directed forgetting. J. Exp. Child Psychol. 62, 292-315. doi: 10.1006/jecp.1996.0032

Harrington, G. S., Farias, D., Davis, C. H., and Buonocore, M. H. (2007). Comparison of the neural basis for imagined writing and drawing. Hum. Brain Mapp. 28, 450-459. doi: 10.1002/hbm.20286

Hasegawa, M., Carpenter, P. A., and Just, M. A. (2002). An fMRI study of bilingual sentence comprehension and workload. Neuroimage 15, 647-660. doi: 10.1006/nimg.2001.1001

Heim, S., Amunts, K., Hensel, T., Grande, M., Huber, W., Binkofski, F., et al. (2012). The role of human parietal area 7A as a link between sequencing in hand actions and in overt speech production. Front. Psychol. 3:534. doi: 10.3389/fpsyg.2012.00534

Hernandez, A. E., Dapretto, M., Mazziotta, J., and Bookheimer, S. (2001). Language switching and language representation in Spanish-English bilinguals: an fMRI study. Neuroimage 14, 510-520. doi: 10.1006/nimg.2001. 0810

Heuvel, M. V. D., Stam, C., Boersma, M., and Hulshoff Pol, H. H. (2008). Small-world and scale-free organization of voxel-based resting-state functional connectivity in the human brain. Neuroimage 43, 528-539. doi: 10.1016/j.neuroimage.2008.08.010

Hoff, E. (2009). Language Development, 4th Edn. Belmont, CA: Wadsworth/ Cengage Learning.

Honey, C. J., Sporns, O., Cammoun, L., Gigandet, X., Thiran, J. P., Meuli, R., et al. (2009). Predicting human resting-state functional connectivity from structural connectivity. Proc. Natl. Acad. Sci. U.S.A. 106, 2035-2040. doi: 10.1073/pnas.0811168106
Horovitz, S. G., Fukunaga, M., de Zwart, J. A., van Gelderen, P., Fulton, S. C., Balkin, T. J., et al. (2008). Low frequency fluctuations during resting wakefulness and light sleep: a simultaneous EEG-fMRI study. Hum. Brain Mapp. 29, 671-682. doi: 10.1002/hbm.20428

Illes, J., Francis, W. S., Desmond, J. E., Gabrieli, J. D., Glover, G. H., Poldrack, R., et al. (1999). Convergent cortical representation of semantic processing in bilinguals. Brain Lang. 70, 347-363. doi: 10.1006/brln.1999. 2186

Indefrey, P., and Levelt, W. J. M. (2004). The spatial and temporal signatures of word production components. Cognition 92, 101-144. doi: 10.1016/j.cognition.2002.06.001

Janata, P., and Grafton, S. T. (2003). Swinging in the brain: shared neural substrates for behaviors related to sequencing and music. Nat. Neurosci. 6, 682-687. doi: $10.1038 / \mathrm{nn} 1081$

January, D., Trueswell, J. C., and Thompson-Schill, S. L. (2009). Co-localization of stroop and syntactic ambiguity resolution in Broca's area: implications for the neural basis of sentence processing. J. Cogn. Neurosci. 21, 2434-2444. doi: 10.1162/jocn.2008.21179

Jurafsky, D. (1996). A probabilistic model of lexical and syntactic access and disambiguation. Cogn. Sci. 20, 137-194. doi: 10.1207/s15516709cog2002_1

Just, M. A., and Carpenter, P. A. (1992). A capacity theory of comprehension: individual differences in working memory. Psychol. Rev. 99, 122-149. doi: 10.1037/0033-295X.99.1.122

Kaakinen, J. K., and Hyönä, J. (2014). Task relevance induces momentary changes in the functional visual field during reading. Psychol. Sci. 25, 626-632. doi: $10.1177 / 0956797613512332$

Kaan, E., and Swaab, T. Y. (2002). The neural circuitry of syntactic comprehension. Trends Cogn. Sci. 6, 350-356. doi: 10.1016/S1364-6613(02)01947-2

Kaas, J. H. (2013). The evolution of brains from early mammals to humans. WIREs 4, 33-45. doi: 10.1002/wcs. 1206

Kail, R. (1991a). "Development of processing speed in childhood and adolescence," in Advances in Child Development and Behavior, Vol. 23, ed H. W. Reese (New York, NY: Academic Press), 151-185.

Kail, R. (1991b). Developmental change in speed of processing during childhood and adolescence. Psychol. Bull. 109, 490-501. doi: 10.1037/0033-2909.109. 3.490

Kail, R. (1991c). Processing time declines exponentially during childhood and adolescence. Dev. Psychol. 27, 259-266. doi: 10.1037/0012-1649.27.2.259

Kail, R., and Salthouse, T. A. (1994). Processing speed as a mental capacity. Acta Psychol. 86, 199-225. doi: 10.1016/0001-6918(94)90003-5

Karmiloff-Smith, A. (1992). Beyond Modularity: A Developmental Perspective on Cognitive Science. Cambridge, MA: MIT Press.

Karmiloff-Smith, A. (2006). "Williams syndrome," in Encyclopedia of Language and Linguistics, 2nd Edn. Vol. 13, ed K. Brown (Oxford: Elsevier), 585-589. doi: 10.1016/B0-08-044854-2/04181-X

Kerns, J. G., Cohen, J. D., Stenger, V. A., and Carter, C. S. (2004). Prefrontal cortex guides context-appropriate responding during language production. Neuron 43 , 283-291. doi: 10.1016/j.neuron.2004.06.032

Khanna, M., and Boland, J. E. (2010). Children's use of language context in lexical ambiguity resolution. Q. J. Exp. Psychol. 63, 160-193. doi: 10.1080/1747021090 2866664

King, J., and Just, M. A. (1991). Individual differences in syntactic processing: the role of working memory. J. Mem. Lang. 30, 580-602. doi: 10.1016/0749596X(91)90027-H

Klein, D., Milner, B., Zatorre, R. J., Zhao,V., and Nikelski, J. (1999). Cerebral organization in bilinguals: a PET study of Chinese-English verb generation. Neuroreport 10, 2841-2845. doi: 10.1097/00001756-199909090-00026

Koechlin, E., Ody, C., and Kouneiher, F. (2003). The architecture of cognitive control in the human prefrontal cortex. Science 302, 1181-1185. doi: 10.1126/science. 1088545

Kotchoubey, B., Lang, S., Bostanov, V., and Birbaumer, N. (2002). Is there a mind? Psychophysiology of unconscious patients. News Physiol. Sci. 17, 38-42.

Kotchoubey, B., Lang, S., Mezger, G., Schmalohr, D., Schneck, M., Semmler, A., et al. (2005). Information processing in severe disorders of consciousness: vegetative state and minimally conscious state. Clin. Neurophysiol. 116, 2441-2453. doi: 10.1016/j.clinph.2005.03.028

Kotchoubey, B., Schneck, M., Lang, S., and Birbaumer, N. (2003). Event-related potentials in a patient with akinetic mutism. Neurophysiol. Clin. 33, 23-30. doi: 10.1016/S0987-7053(03)00003-0 
Kriegeskorte, N., Simmons, W. K., Bellgowan, P. S. F., and Baker, C. I. (2009). Circular analysis in systems neuroscience-the dangers of double dipping. Nat. Neurosci. 12, 535-540. doi: 10.1038/nn.2303

Kucera, H., and Francis, W. N. (1967). Computational Analysis of Present-day American Engish. Providence: Brown University Press.

Kuhl, P. K. (2004). Early language acquisition: cracking the speech code. Nat. Rev. Neurosci. 5, 831-843. doi: 10.1038/nrn1533

Kuperberg, G. R., Holcomb, P. J., Sitnikova, T., Greve, D., Dale, A. M., and Caplan, D. (2003). Distinct patterns of neural modulation during the processing of conceptual and syntactic anomalies. J. Cogn. Neurosci. 15, 272-293. doi: 10.1162/089892903321208204

Lashley, K. S. (1929). Brain Mechanisms and Intelligence. Chicago, IL: University of Chicago Press.

Laureys, S., Perrin, F., Schnakers, C., Boly, M., and Majerus, S. (2005). Residual cognitive function in comatose, vegetative and minimally conscious states. Curr. Opin. Neurol. 18, 726-733. doi: 10.1097/01.wco.0000189874.92362.12

Levy, R. (2008). Expectation-based syntactic comprehension. Cognition 106, 1126-1177. doi: 10.1016/j.cognition.2007.05.006

Levy, R., Fedorenko, E., and Gibson, E. (2014). The syntactic complexity of Russian relative clauses. J. Mem. Lang. 69, 461-495. doi: 10.1016/j.jml.2012.10.005

Lewis, R., Vasishth, S., and Van Dyke, J. (2006). Computational principles of working memory in sentence comprehension. Trends Cogn. Sci. 10, 447-454. doi: 10.1016/j.tics.2006.08.007

Listerud, J., Powers, C., Moore, P., Libon, D. J., and Grossman, M. (2009). Neuropsychological patterns in magnetic resonance imaging-defined subgroups of patients with degenerative dementia. J. Int. Neuropsychol. Soc. 15, 459-470. doi: 10.1017/S1355617709090742

Luciana, M., Conklin, H. M., Hooper, C. J., and Yarger, R. S. (2005). The development of nonverbal working memory and executive control processes in adolescents. Child Dev. 76, 697-712. doi: 10.1111/j.1467-8624.2005. 00872.x

Luciana, M., and Nelson, C. A. (2002). Assessment of neuropsychological function in children using the Cambridge Neuropsychological Testing Automated Battery (CANTAB): performance in 4 to 12 year-olds. Dev. Neuropsychol. 22, 595-623. doi: 10.1207/S15326942DN2203_3

Luna, B., Garver, K. E., Urban, T. A., Lazar, N. A., and Sweeney, J. A. (2004). Maturation of cognitive processes from late childhood to adulthood. Child Dev. 75, 1357-1372. doi: 10.1111/j.1467-8624.2004.00745.x

Luria, A. R. (1966). Higher Cortical Functions in Man. Trans. B. Haigh New York, NY: Basic Books.

Lyons-Warren, A., Lillie, R., and Hershey, T. (2004). Short and long-term spatial delayed response performance across the lifespan. Dev. Neuropsychol. 26, 661-678. doi: 10.1207/s15326942dn2603_1

MacDonald, M. C., Almor, A., Henderson, V. W., Kempler, D., and Andersen, E. S. (2001). Assessing working memory and language comprehension in Alzheimer's disease. Brain Lang. 78, 17-42. doi: 10.1006/brln.2000.2436

MacDonald, M., Pearlmutter, N., and Seidenberg, M. (1994). Lexical nature of syntactic ambiguity resolution. Psychol. Rev. 103, 676-703. doi: 10.1037/0033295X.101.4.676

Mahendra, N., Plante, E., Magloire, J., Milman, L., and Trouard, T. (2003). MRI variability and the localization of languages in the bilingual brain. Neuroreport 14, 1225-1228. doi: 10.1097/00001756-200307010-00007

Mariotti, P., Iuvone, L., Torrioli, M. G., and Silveri, M. C. (1998). Linguistic and non-linguistic abilities in a patient with early left hemispherectomy. Neuropsychologia 36, 1303-1312. doi: 10.1016/S0028-3932(98)00031-1

McCandliss, B. D., Cohen, L., and Dehaene, S. (2003). The visual word form area: expertise for reading in the fusiform gyrus. Trends Cogn. Sci. 7, 293-299. doi: 10.1016/S1364-6613(03)00134-7

McElree, B., Foraker, S., and Dyer, L. (2003). Memory structures that subserve sentence comprehension. J. Mem. Lang. 48, 67-91. doi: 10.1016/S0749596X(02)00515-6

McMillan, C. T., Clark, R., Gunawardena, D., Ryant, N., and Grossman, M. (2012). fMRI evidence for strategic decision-making during resolution of pronoun reference. Neuropsychologia 50, 674-687. doi: 10.1016/j.neuropsychologia.2012.01.004

McMillan, C. T., Coleman, D., Clark, R., Liang, T.-W., Gross, R. G., and Grossman, M. (2013) Converging evidence for the processing costs associated with ambiguous quantifier comprehension. Front. Psychol. 4:153. doi: 10.3389/fpsyg.2013.00153
McVay, J. C., and Kane, M. J. (2012). Why does working memory capacity predict variation in reading comprehension? On the influence of mind wandering and executive attention. J. Exp. Psychol. 141, 302-320. doi: 10.1037/ a0025250

Meister, I. G., Krings, T., Foltys, H., Boroojerdi, B., Müller, M., Töpper, R., et al. (2004). Playing piano in the mind-an fMRI study on music imagery and performance in pianists. Brain Res. Cogn. Brain Res. 19, 219-228. doi: 10.1016/j.cogbrainres.2003.12.005

Mervis, C. B., and Becerra, A. M. (2007). Language and communicative development in Williams syndrome. Ment. Retard. Dev. Disabil. Res. Rev. 13, 3-15. doi: 10.1002/mrdd.20140

Mesulam, M.-M. (2001). Primary progressive aphasia. Ann. Neurol. 49, 425-432. doi: 10.1002/ana.91

Miller, E. K., and Cohen, J. D. (2001). An integrative theory of prefrontal cortex function. Annu. Rev. Neurosci. 24, 167-202. doi: 10.1146/annurev.neuro.24. 1.167

Miyake, A., Friedman, N. P., Emerson, M. J., Witzki, A. H., Howerter, A., and Wager T. D. (2000). The unity and diversity of executive functions and their contributions to complex "frontal lobe" tasks: a latent variable analysis. Cogn. Psychol. 41, 49-100. doi: 10.1006/cogp.1999.0734

Money, J. (1964). Two cytogenetic syndromes: psychologic comparisons. I. Intelligence and specific-factor quotients. J. Psychiat. Res. 2, 223-231. doi: 10.1016/0022-3956(64)90022-6

Money, J., and Alexander, D. (1966). Turner's syndrome: further demonstration of the presence of specific cognitional deficiencies. J. Med. Genet. 3, 47-48. doi: 10.1136/jmg.3.1.47

Montgomery, J. W. (2003). Working memory and comprehension in children with specific language impairment: what we know so far. J. Commun. Disord. 36, 221-231. doi: 10.1016/S0021-9924(03)00021-2

Monti, M. M., Parsons, L. M., and Osherson, D. N. (2012). Thought beyond language: Neural dissociation of algebra and natural language. Psychol. Sci. 23, 914-922. doi: 10.1177/0956797612437427

Müller, R. A., Rothermel, R. D., Behen, M. E., Muzik, O., Mangner, T. J., and Chugani, H. T. (1997). Receptive and expressive language activations for sentences: a PET study. Neuroreport 8, 3767-3770. doi: 10.1097/00001756199712010-00022

Munoz, D., Broughton, J., Goldring, J., and Armstrong, I. (1998). Age-related performance of human subjects on saccadic eye movement tasks. Exp. Brain Res. $217,1-10$.

Murphy, M. (2009). Language and literacy in Turner syndrome. Top. Lang. Disord. 29, 187-194. doi: 10.1097/TLD.0b013e3181a720aa

Myachykov, A., and Posner, M. I. (2005). "Attention in language," in Neurobiology of Attention, eds L. Itti, G. Rees, and J. Tsotsos (Waltham, MA: Academic Press, Elsevier), 324-329.

Nestor, P. J., Graham, N. L., Fryer, T. D., Williams, G. B., Patterson, K., and Hodges, J. R. (2003). Progressive non-fluent aphasia is associated with hypometabolism centred on the left anterior insula. Brain 126, 2406-2418. doi: 10.1093/brain/awg240

Neumann, N., and Kotchoubey, B. (2004). Assessment of cognitive functions in severely paralysed and severely brain-damaged patients: neuropsychological and electrophysiological techniques. Brain Res. Protoc. 14, 25-36. doi: 10.1016/j.brainresprot.2004.09.001

Neville, H. J., Bavelier, D., Corina, D., Rauschecker, J., Karni, A., Lalwani, A., et al (1998). Cerebral organization for language in deaf and hearing subjects: biological constraints and effects of experience. Proc. Natl. Acad. Sci. U.S.A. 95, 922-929. doi: 10.1073/pnas.95.3.922

Newman, A. J., Kenny, S., Saint-Aubin, J., and Klein, R. M. (2013). Can skilled readers perform a second task in parallel? A functional connectivity MRI study. Brain Lang. 124, 84-95. doi: 10.1016/j.bandl.2012.11.009

Newman, A. J., Supalla, T., Hauser, P., Newport, E. L., and Bavelier, D. (2010). Dissociating neural subsystems for grammar by contrasting word order and inflection. Proc. Natl. Acad. Sci. U.S.A. 107, 7539-7544. doi: 10.1073/pnas. 1003174107

Newport, E. L. (1990). Maturational constraints on language learning. Cogn. Sci. 14, 11-28. doi: 10.1207/s15516709 $\operatorname{cog} 1401 \_2$

Nieto-Castañon, A., and Fedorenko, E. (2012). Subject-specific functional localizers increase sensitivity and functional resolution of multi-subject analyses. Neuroimage 63, 1646-1669. doi: 10.1016/j.neuroimage.2012. 06.065 
Nieuwland, M. S., Martin, A. E., and Carreiras, M. (2012). Brain regions that process case: evidence from Basque. Hum. Brain Mapp. 33, 2509-2520. doi: 10.1002/hbm.21377

Nobre, A. C., Allison, T., and McCarthy, G. (1994). Word recognition in the human inferior temporal lobe. Nature 372, 260-263. doi: 10.1038/372260a0

Noppeney, U., and Price, C. J. (2004). Retrieval of abstract semantics. Neuroimage 22, 164-170. doi: 10.1016/j.neuroimage.2003.12.010

Novais-Santos, S., Gee, J., Shah, M., Troiani, V., Work, M., and Grossman, M. (2007). Resolving sentence ambiguity with planning and working memory resources: evidence from fMRI. Neuroimage 37, 361-378. doi: 10.1016/j.neuroimage.2007.03.077

Novick, J. M., Kan, I. P., Trueswell, J. C., and Thompson-Schill, S. L. (2009). A case for conflict across multiple domains: memory and language impairments following damage to ventrolateral prefrontal cortex. Cogn. Neuropsychol. 26 527-567. doi: 10.1080/02643290903519367

Novick, J. M., Trueswell, J. C., and Thompson-Schill, S. L. (2005). Cognitive control and parsing: reexamining the role of Broca's area in sentence comprehension. Cogn. Affect. Behav. Neurosci. 5, 263-281. doi: 10.3758/CABN.5.3.263

Novick, J. M., Trueswell, J. C., and Thompson-Schill, S. L. (2010). Broca's area and language processing: evidence for the cognitive control connection. Lang. Linguist. Compass 4, 906-924. doi: 10.1111/j.1749-818X.2010.00244.x

Ojemann, J. G., Buckner, R. L., Akbudak, E., Snyder, A. Z., Ollinger, J. M., Mckinstry, R. C., et al. (1998). Functional MRI studies of word stem completion: reliability across laboratories and comparison to blood flow imaging with PET. Hum. Brain Mapp. 6, 603-215.

Palermo, R., and Rhodes, G. (2007). Are you always on my mind? a review of how face perception and attention interact. Neuropsychologia 45, 75-92. doi: 10.1016/j.neuropsychologia.2006.04.025

Park, D. C., Lautenschlager, G., Hedden, T., Davidson, N. S., Smith, A. D., and Smith, P. K. (2002). Models of visuospatial and verbal memory across the adult life span. Psychol. Aging 17, 299-320. doi: 10.1037/0882-7974.17.2.299

Patterson, K., Nestor, P., and Rogers, T. (2007). Where do you know what you know? The representation of semantic knowledge in the human brain. Nat. Rev. Neurosci. 8, 976-987. doi: 10.1038/nrn2277

Peelle, J. E., Troiani, V., Wingfield, A., and Grossman, M. (2010). Neural processing during older adults' comprehension of spoken sentences: age differences in resource allocation and connectivity. Cereb. Cortex 20, 773-782. doi: 10.1093/ cercor/bhp 142

Petersen, S. E., and Fiez, J. A. (1993). The processing of single words studied with positron emission tomography. Annu. Rev. Neurosci. 16, 509-530. doi: 10.1146/annurev.ne.16.030193.002453

Petersen, S. E., Fox, P. T., Posner, M. I., Mintun, M., and Raichle, M. E. (1988). Positron emission tomographic studies of the cortical anatomy of single-word processing. Nature 331, 585-589. doi: 10.1038/331585a0

Petersen, S. E., Fox, P. T., Snyder, A. Z., and Raichle, M. E. (1990). Activation of extrastriate and frontal cortical areas by visual words and word-like stimuli. Science 249, 1041-1044. doi: 10.1126/science.2396097

Petersen, S. E., and Posner, M. I. (2012). The attention system of the human brain: 20 years after. Annu. Rev. Neurosci. 35, 73-89. doi: 10.1146/annurev-neuro062111-150525

Piantadosi, S. T., Tily, H., and Gibson, E. (2012). The communicative function of ambiguity in language. Cognition 122, 280-291. doi: 10.1016/j.cognition.2011.10.004

Pinel, P., Thirion, B., Meriaux, S., Jobert, A., Serres, J., Le Bihan, D., et al. (2007) Fast reproducible identification and large-scale databasing of individual functional cognitive networks. BMC Neurosci. 8:91. doi: 10.1186/1471-2202-8-91

Pinker, S. (1994). The Language Instinct: How the Mind Creates Language. New York, NY: HarperCollins.

Posner, M. I., and Petersen, S. E. (1990). The attention system of the human brain. Annu. Rev. Neurosci. 13, 25-42. doi: 10.1146/annurev.ne.13.030190.000325

Power, J. D., Cohen, A. L., Nelson, S. M., Wig, G. S., Barnes, K. A., Church, J. A., et al. (2011). Functional network organization of the human brain. Neuron 72 , 665-678. doi: 10.1016/j.neuron.2011.09.006

Preston, K. A. (1935). The speed of word perception and its relation to reading ability. J. Gene. Psychol. 13, 199-203. doi: 10.1080/00221309.1935.9917878

Pu, Y., Liu, H.-L., Spinks, J. A., Mahankali, S., Xiong, J., Feng, C.-M., et al. (2001). Cerebral hemodynamic response in Chinese (first) and English (second) language processing revealed by event-related functional MRI. Magn. Reson. Imaging 19, 643-647. doi: 10.1016/S0730-725X(01)00379-4
Pulvermüller, F., Shtyrov, Y., Hasting, A., and Carlyon, R. P. (2008). Syntax as a reflex: neurophysiological evidence for early automaticity of grammatical processing. Brain Lang. 104, 244-253. doi: 10.1016/j.bandl.2007.05.002

Rasmussen, T., and Milner, B. (1977). The role of early left-brain injury in determining lateralization of cerebral speech functions. Ann. N.Y. Acad. Sci. 299, 355-369. doi: 10.1111/j.1749-6632.1977.tb41921.x

Reichle, E., Reineberg, A. E., and Schooler, J. W. (2010). An eye-movement study of mindless reading. Psychol. Sci. 21, 1300-1310. doi: 10.1177/0956797610378686

Ridderinkhof, R. K., Forstmann, B. U., Wylie, S. A., Burle, B., and van den Wildenberg, W. P. M. (2011). Neurocognitive mechanisms of action control: resisting the call of the Sirens. WIREs 2, 174-192. doi: 10.1002/wcs.99

Rigotti, M., Rubin, D. B. D., Wang, X.-J., and Fusi, S. (2010). Internal representation of task rules by recurrent dynamics: the importance of the diversity of neural responses. Front. Comput. Neurosci. 4:24. doi: 10.3389/fncom.2010.00024

Robertson, D. A., Gernsbacher, M. A., Guidotti, S. J., Robertson, R. R., Irwin, W., Mock, B. J., et al. (2000). Functional neuroanatomy of the cognitive process of mapping during discourse comprehension. Psychol. Sci. 11, 255-260. doi: $10.1111 / 1467-9280.00251$

Rodd, J. M., Davis, M. H., and Johnsrude, I. S. (2005). The neural mechanisms of speech comprehension: fMRI studies of semantic ambiguity. Cereb. Cortex 15, 1261-1269. doi: 10.1093/cercor/bhi009

Roelofs, A., and Piai, V. (2011). Attention demands of spoken word planning: a review. Front. Psychol. 2:307. doi: 10.3389/fpsyg.2011.00307

Rogalski, E., Cobia, D., Harrison, T. M., Wieneke, C., Thompson, C. K., Weintraub, S., et al. (2011). Anatomy of language impairments in primary progressive aphasia. J. Neurosci. 31, 3344-3350. doi: 10.1523/JNEUROSCI.5544-10.2011

Rogalsky, C., and Hickok, G. (2011). The role of Broca's area in sentence comprehension. J. Cogn. Neurosci. 23, 1664-1680. doi: 10.1162/jocn.2010.21530

Rohde, D. L. T., and Plaut, D. C. (1999). Language acquisition in the absence of explicit negative evidence: how important is starting small? Cognition 72, 67-109. doi: 10.1016/S0010-0277(99)00031-1

Rohrer, J. D., Warren, J. D., Modat, M., Ridgway, G. R., Douiri, A., Rossor, M. N., et al. (2009). Patterns of cortical thinning in the language variants of frontotemporal lobar degeneration. Neurology 72, 1562-1569. doi: 10.1212/WNL.0b013e3181a4124e

Roland, D., Dick, F., and Elman, J. (2007). Frequency of basic English grammatical structures: a corpus analysis. J. Mem. Lang. 57, 348-379. doi: 10.1016/j.jml.2007.03.002

Rondal, J. A. (1994). "Exceptional cases of language development in mental retardation: the relative autonomy of language as a cognitive system," in Constraints on Language Development: Studies of Atypical Children, ed H. Tager-Flusberg (Hillsdale, NJ: Erlbaum Associates), 155-174.

Rondal, J. A. (1995). Exceptional Language Development in Down Syndrome. Implications for the Cognition Language Relationship. New York, NY: Cambridge University Press. doi: 10.1017/CBO9780511582189

Ronnlund, M., Nyberg, L., Backman, L., and Nilsson, L. G. (2005). Stability, growth, and decline in adult life span development of declarative memory: Cross-sectional and longitudinal data from a population-based study. Psychol. Aging 20, 3-18. doi: 10.1037/0882-7974.20.1.3

Rosenberg, S. (1982). "The language of the mentally retarded: Development, processes and intervention." in Handbook of Applied Psycholinguistics, ed S. Rosenberg (Hillsdale, NJ: Erlbaum), 329-392.

Roy, J. E., Riesenhuber, M., Poggio, T., and Miller, E. K. (2010) Prefrontal cortex activity during flexible categorization. J. Neuroscience 30, 8519-8528. doi: 10.1523/JNEUROSCI.4837-09.2010

Ryan, J. (1975). "Mental subnormality and language development," in Foundations of Language Development, eds E. Lenneberg and E. Lenneberg, Vol. 2. (New York, NY: Academic Press), 269-277.

Schiff, N. D., Rodriguez-Moreno, D., Kamal, A., Kim, K. H., Giacino, J. T., Plum, F., et al. (2005). fMRI reveals large-scale network activation in minimally conscious patients. Neurology 64, 514-523. doi: 10.1212/01.WNL.0000150883.10285.44

Schwartz, M. F., Marin, O. S., and Saffran, E. M. (1979). Dissociations of language function in dementia: a case study. Brain Lang. 7, 277-306. doi: 10.1016/0093934X(79)90024-5

Schwarzlose, R., Baker, C., and Kanwisher, N. (2005). Separate face and body selectivity on the fusiform gyrus. J. Neurosci. 25, 11055-11059. doi: 10.1523/JNEUROSCI.2621-05.2005

Searleman, A. (1977). A review of right hemisphere linguistic capabilities. Psychol. Bull. 84, 503-528. doi: 10.1037/0033-2909.84.3.503 
Sebastian, R., Laird, A. R., and Kiran, S. (2011). Meta-analysis of the neural representation of first language and second language. Appl. Psycholinguistics 32, 799-819. doi: 10.1017/S0142716411000075

Seeley, W. W., Crawford, R. K., Zhou, J., Miller, B. L., and Greicius, M. D. (2009). Neurodegenerative diseases target large-scale human brain networks. Neuron 62, 42-52. doi: 10.1016/j.neuron.2009.03.024

Seigneuric, A. S., Ehrlich, M. F., Oakhill, J. V., and Yuill, N. M. (2000). Working memory resources and children's reading comprehension. Read. Writ. 13, 81-103. doi: 10.1023/A:1008088230941

Shapiro, K. A., Moo, L. R., and Caramazza, A. (2006). Cortical signatures of noun and verb production. Proc. Natl. Acad. Sci. U.S.A. 103, 1644-1649. doi: 10.1073/pnas.0504142103

Sharp, D. J., Turkheimer, F. E., Bose, S. K., Scott, S. K., and Wise, R. J. (2010) Increased frontoparietal integration after stroke and cognitive recovery. Ann. Neurol. 68, 753-756. doi: 10.1002/ana.21866

Shtyrov, Y., and Pulvermüller, F. (2007). Early activation dynamics in the left temporal and inferior-frontal cortex reflect semantic context integration. J. Cogn. Neurosci. 19, 1633-1642. doi: 10.1162/jocn.2007.19.10.1633

Shuster, L. I., and Lemieux, S. K. (2005). An fMRI investigation of covertly and overtly produced mono- and multisyllabic words. Brain Lang. 93, 20-31. doi: 10.1016/j.bandl.2004.07.007

Smith, N. J., and Levy, R. (2013). The effect of word predictability on reading time is logarithmic. Cognition 128, 302-319. doi: 10.1016/j.cognition.2013. 02.013

Smith, N. V., and Tsimpli, I. M. (1995). The Mind of a Savant: Language Learning and Modularity. Oxford, UK: Blackwell.

Snijders, T. M., Vosse, T., Kempen, G., Van Berkum, J. J. A., Petersson, K. M., and Hagoort, P. (2009). Retrieval and unification of syntactic structure in sentence comprehension: an fMRI study using word-category ambiguity. Cereb. Cortex 19, 1493-1503. doi: 10.1093/cercor/bhn187

Sporns, O. (2010). Networks of the Brain. Cambridge, MA: MIT Press.

Sporns, O., Honey, C., Kötter, R., and Kaiser, M. (2007). Identification and classification of hubs in brain networks. PLoS ONE 2:e1049. doi: 10.1371/journal.pone.0001049

Srihasam, K., Mandeville, J. B., Morocz, I. A., Sullivan, K. J., and Livingstone, M. S. (2011). Behavioral and anatomical consequences of early versus late symbol training in macaques. Neuron 73, 608-619. doi: 10.1016/j.neuron.2011. 12.022

Stiers, P., Mennes, M., and Sunaert, S. (2010). Distributed task coding throughout the multiple demand network of the human frontal-insular cortex. Neuroimage 52, 252-262. doi: 10.1016/j.neuroimage.2010.03.078

Strijkers, K., Yum, Y. N., Grainger, J., and Holcomb, P. J. (2011). Early goal-directed top-down influences in the production of speech. Front. Psychol. 2:371. doi 10.3389/fpsyg.2011.00371

Suzuki, S., and Cavanagh, P. (1995). Facial organization blocks access to low-level features: an object inferiority effect. J. Exp. Psychol. Hum. Percep. Perform. 21, 901-913. doi: 10.1037/0096-1523.21.4.901

Temperley, D. (2007). Minimization of dependency length in written english. Cognition 105, 300-333. doi: 10.1016/j.cognition.2006.09.011

Treisman, A. (1964). Monitoring and storage of irrelevant messages in selective attention. J. Verbal Learn. Verbal Behav. 3, 449-201. doi: 10.1016/S00225371(64)80015-3

Tremblay, P., and Small, S. L. (2011). Motor response selection in overt sentence production: a functional MRI study. Front. Psychol. 2:253. doi: 10.3389/fpsyg.2011.00253

Troiani, V., Fernández-Seara, M. A., Wang, Z., Detre, J. A., Ash, S. and Grossman, M. (2008). Narrative speech production: an fMRI study using continuous arterial spin labeling. Neuroimage 40, 932-939. doi: 10.1016/j.neuroimage.2007.12.002

Trueswell, J. C., and Tanenhaus, M. K. (1994). "Toward a lexicalist framework for constraint-based syntactic ambiguity resolution," in Perspectives in Sentence Processing, eds C. Clifton, L. Frazier, and K. Rayner (Hillsdale, NJ: Lawrence Erlbaum Assoc.), 155-179.

Turken, A. U., and Dronkers, N. F. (2011). The neural architecture of the language comprehension network: converging evidence from lesion and connectivity analyses. Front. Syst. Neurosci 5:1. doi: 10.3389/fnsys.2011.00001

Uttl, B. (2002). North american adult reading test: age norms, reliability, and validity. J. Clin. Exp. Neuropsychol. 24, 1123-1137. doi: 10.1076/jcen.24.8.1123. 8375
Vallar, G., and Shallice, T. (eds.). (1990). Neuropsychological Impairments of Short-Term Memory. New York, NY: Cambridge University Press. doi: 10.1017/CBO9780511665547

van Heuven, W. J. B., and Dijkstra, T. (2010). Language comprehension in the bilingual brain: fMRI and ERP support for psycholinguistic models. Brain Res. Rev 64, 104-122. doi: 10.1016/j.brainresrev.2010.03.002

van Horik, J., and Emery, N. (2011). Evolution of cognition. WIREs 2, 621-633. doi: $10.1002 /$ wcs. 144

Van Lancker-Sidtis, D. (2004). When only the right hemisphere is left: language and communication studies. Brain Lang. 91, 199-211. doi: 10.1016/j.bandl.2004.02.006

Verhaeghen, P. (2003). Aging and vocabulary scores: a meta-analysis. Psychol. Aging 18, 332-339. doi: 10.1037/0882-7974.18.2.332

Vincent, J. L., Patel, G. H., Fox, M. D., Snyder, A. Z., Baker, J. T., Van Essen, D. C., et al. (2007). Intrinsic functional architecture in the anesthetized monkey brain. Nature 447, 83-86. doi: 10.1038/nature05758

Von Arnim, G., and Engel, P. (1964). Mental retardation is related to hypercalcemia. Dev. Med. Child Neurol. 6, 366-377. doi: 10.1111/j.1469-8749.1964. tb08138.x

Vuong, L. C., and Martin, R. C. (2011). LIFG-based attentional control and the resolution of lexical ambiguities in sentence context. Brain Lang. 116, 22-32. doi: 10.1016/j.bandl.2010.09.012

Wada, J. (1949). A new method for the determination of the side of cerebral speech dominance. A preliminary report of the intra-carotid injection of sodium amytal in man. Igaku Seibutsugaki 14, 221-222.

Wanner, E., and Maratsos, M. (1978). "An ATN approach to comprehension," in Linguistic Theory and Psychological Reality, eds M. Halle, G. Miller, and J. Bresnan (Cambridge, MA: MIT Press), 122-141.

Waters, G., and Caplan, D. (1996). Processing resource capacity and the comprehension of garden path sentences. Mem. Cognit. 24, 342-355. doi: $10.3758 / \mathrm{BF} 03213298$

Waters, G., Caplan, D., and Hildebrandt, N. (1987). "Working memory and written sentence comprehension," in Attention and Performance XII: The Psychology of Reading, ed M. Coltheart (London: Erlbaum), 531-555.

Wernicke, C. (1874/1969). "The symptom complex of aphasia: a psychological study on an anatomical basis," in Boston Studies in the Philosophy of Science, eds R. S. Cohen and M. W. Wartofsky (Dordrecht: D. Reidel Publishing Company), 34-97.

Whitehouse, P., Caramazza, A., and Zurif, E. (1978). Naming in aphasia: interacting effects of form and function. Brain Lang. 6, 63-74. doi: 10.1016/0093934X(78)90044-5

Wild, C. J., Yusuf, A., Wilson, D., Peelle, J. E., Davis, M. H., and Johnsrude, I. S. (2012). Effortful listening: the processing of degraded speech depends critically on attention. I. Neurosci. 32, 14010-14021. doi: 10.1523/JNEUROSCI.152812.2012

Wilson, S. M., Henry, M. L., Besbris, M., Ogar, J. M., Dronkers, N. F., Jarrold, W., et al. (2010). Connected speech production in three variants of primary progressive aphasia. Brain 133, 2069-2088. doi: 10.1093/brain/ awq129

Wilson, S. M., Isenberg, A. L., and Hickok, G. (2009). Neural correlates of word production stages delineated by parametric modulation of psycholinguistic variables. Hum. Brain Mapp. 30, 3596-3608. doi: 10.1002/hbm. 20782

Wingfield, A., and Grossman, M. (2006). Language and the aging brain: Patterns of neural compensation revealed by functional brain imaging. J. Neurophysiol. 96, 2830-2839. doi: 10.1152/jn.00628.2006

Wisniewski, K. E., Miezejeski, C. M., and Hill, A. L. (1988). "Neurological and psychological status of individuals with Down syndrome," in The psychobiology of Down Syndrome, ed L. Nadel (Cambridge, MA: MIT Press), 315-343.

Wojciulik, E., and Kanwisher, N. (1999) The generality of parietal involvement in visual attention. Neuron 23, 747-764. doi: 10.1016/S0896-6273(01)80033-7

Woolgar, A., Parr, A., Thompson, R., Cusack, R., Nimmo-Smith, I., Antoun, N. et al. (2010). Fluid intelligence loss linked to restricted regions of damage within frontal and parietal cortex. Proc. Natl. Acad. Sci. U.S.A. 107, 14899-14902. doi: $10.1073 /$ pnas. 1007928107

Wotschack, C. (2009). Eye Movements in Reading Strategies: How Reading Strategies Modulate Effects of Distributed Processing and Oculomotor Control. Potsdam: Universitätsverlag Potsdam. 
Yamada, J. E. (1990). Laura: A Case for the Modularity of Language. Cambridge, MA: MIT Press.

Zelazo, P. D., Craik, F. I. M., and Booth, L. (2004). Executive function across the life span. Acta Psychol. 115, 167-183. doi: 10.1016/j.actpsy.2003.12.005

Ziegler, W., Kilian, B., and Deger, K. (1997). The role of the left mesial frontal cortex in fluent speech: evidence from a case of left supplementary motor area hemorrhage. Neuropsychologia 35, 1197-1208. doi: 10.1016/S0028-3932(97)00040-7

Conflict of Interest Statement: The author declares that the research was conducted in the absence of any commercial or financial relationships that could be construed as a potential conflict of interest.
Received: 31 October 2012; accepted: 31 March 2014; published online: 28 April 2014. Citation: Fedorenko $E$ (2014) The role of domain-general cognitive control in language comprehension. Front. Psychol. 5:335. doi: 10.3389/fpsyg.2014.00335

This article was submitted to Language Sciences, a section of the journal Frontiers in Psychology.

Copyright (0) 2014 Fedorenko. This is an open-access article distributed under the terms of the Creative Commons Attribution License (CC BY). The use, distribution or reproduction in other forums is permitted, provided the original author(s) or licensor are credited and that the original publication in this journal is cited, in accordance with accepted academic practice. No use, distribution or reproduction is permitted which does not comply with these terms. 